\title{
FACTORS AFFECTING LABOR SUPPLY DECISIONS AND RETIREMENT INCOME
}

Robin L. Lumsdaine

Working Paper No. 5223

\author{
NATIONAL BUREAU OF ECONOMIC RESEARCH \\ 1050 Massachusetts Avenue \\ Cambridge, MA 02138 \\ August 1995
}

This paper was prepared for the National Academy of Sciences, Committee on National Statistics' Panel on Retirement Income Modeling. Financial support from the National Institute on Aging, grant number R37-AG00146, and the Center for Economic Policy Studies at Princeton University is gratefully acknowledged. This paper has benefitted substantially from comments on earlier drafts by Constance Citro, Marjorie Honig, John Rust, and participants at the National Academy of Sciences' conference held in Washington, DC, September 29-30, 1994. This paper is part of NBER's research program in Aging. Any opinions expressed are those of the author and not those of the National Bureau of Economic Research.

() 1995 by Robin L. Lumsdaine. All rights reserved. Short sections of text, not to exceed two paragraphs, may be quoted without explicit permission provided that full credit, including $\odot$ notice, is given to the source. 


\title{
FACTORS AFFECTING LABOR SUPPLY DECISIONS AND RETIREMENT INCOME
}

\begin{abstract}
Recent policy has focused on alleviating poverty among the elderly, with varying degrees of success. Gains to some subsets of the elderly population have come at the expense of others. A component of the policy debate has been identifying factors which might influence labor force participation decisions and the effects such decisions will have on retirement income and its adequacy for a growing elderly population. While models of retirement behavior are becoming increasingly sophisticated, most fail to capture key elements such as expectations and uncertainty. This is in part due to the reduced form nature of policy experiments; parameters are estimated under a current policy and used to predict effects of an alternative scenario. Such an approach implicitly assumes that the only difference in the alternative setting is the change in policy and does not adequately account for endogeneity of decisions and responses to these changes. This paper reviews factors affecting the labor supply decision, their interactions with and implications for subsequent retirement income, and identifies important methods and data requirements necessary to model complicated dynamic behavior more accurately.
\end{abstract}

Robin L. Lumsdaine

Department of Economics

Princeton University

Princeton, NJ 08544

and NBER 


\section{Factors Affecting Labor Supply Decisions and Retirement Income}

\section{Introduction}

Recent retirement research has focussed on factors affecting the retirement decision, reflecting the notion that retirement has become voluntary (Quinn, Burkhauser, and Myers [1990] document the transition over the last four decades from retirement due to health reasons - "involuntary" - to the current status of choosing to retire). Leonesio [1993a] cites the "life-cycle view of work, saving, and consumption" as the motivating influence behind the behavioral focus of the retirement literature, particularly with regard to decisions about Social Security, pensions, leaving a career job, and accepting postretirement work. Recognizing the life-cycle view, economists have concentrated not just on the final decision regarding labor force participation, but on the individual's whole history of labor force participation decisions.

Due to both the projected shortfall in Social Security and an overall anticipated labor shortage, recent policy has focussed on ways to alter these labor supply decisions, particularly with regard to affecting retirement behavior and income. Gustman, Mitchell, and Steinmeier [1994] and Hurd [1993] identify some of the factors that influence the retirement decision. Gustman, Mitchell, and Steinmeier consider factors affecting the individual, such as health status, retirement status of spouse, additional family needs, and the individual's savings and consumption patterns, while Hurd surveys some of the institutional causes that lead individuals to retire at different ages, such as fixed employment costs, the Social Security earnings test, and pre-existing condition clauses in health insurance. In addition, the perceived financial condition of the employer may play a role in an individual's decision to leave the firm.

This paper examines the determinants of some of the key labor supply decisions and their relationship to retirement behavior and retirement income. In order to determine which policies will have the most desirable effects at the lowest cost, we need to assess the relationships and interactions among direct and indirect influences. Some of the questions that have been debated are the following: Will increasing the Social Security 
early and normal retirement ages create a substitution toward increased disability applications? Have increasing life expectancies resulted in more productive years of life or just prolonged years of non-work life? Is the relationship between longevity and work ability becoming weaker as labor intensive jobs are a smaller proportion of available jobs? How do individuals formulate expectations about the future and how do they incorporate uncertainty into their decisions? What will be the impact on labor force participation of universal health coverage?

This paper will investigate the data and research methodology needed to answer questions such as these. The first section summarizes some of the trends in factors affecting labor force participation decisions and retirement income. Being able to predict future trends is critical to forecasting the success of proposed changes in policy aimed at ensuring adequate retirement income. The following five sections focus on specific key areas that potentially affect the labor supply decision, the transition to retirement, and associated retirement income: Social Security, pensions and early retirement "window" plans, disability, Medicare and other forms of health insurance, and job characteristics. Each of these sections begins with a summary of questions and currently available techniques for addressing them. I then identify future research priorities, focussing on data and methods necessary to understand the extent of the interaction among these areas and how policies aimed at specific areas will ultimately affect retirement behavior and income. The final section concludes.

\section{Summary of Trends}

While legislation over the last few decades has aimed to reduce the incidence of poverty among the elderly, the threat of poverty has not been eradicated, as shown in Figure 1. As individuals age, the probability of being at or near the poverty line increases substantially. One group of elderly particularly at risk are the nearly one-third of Americans over age 65 that live alone, most often women.

"For the millions of elderly people who live alone, the threats of impoverishment, loss of independence, loneliness and isolation are very real. Many have serious 
health and economic problems that our society and our governments are neglecting. These conditions persist despite the substantial improvements that Social Security and health and income assistance programs have made in the lives of most older Americans over the past 20 years" (Kasper [1988]).

Women currently account for more than four-fifths of the elderly living alone, as seen in Figure 2. Poverty rates are also expected to be concentrated on single women in the future, despite expectations that the elderly as a group will have higher standards of living than previous cohorts (Kingson [1992]). Radner [1993b] considers income, wealth, and combined income-wealth measures and finds that the economic status of widows living alone is significantly worse than that of other groups of elderly.

Across all ages, uncertainty about Social Security is increasing. Concerns over the budget deficit have threatened the current levels of Social Security benefits. Even holding benefits at their current levels, the aging of the baby boom population poses an additional strain on the Social Security trust fund. Combined, these two concerns have undermined confidence regarding adequate income for future generations of elderly.

Despite concerns over the adequacy of Social Security retirement income, the wealth of the elderly remains surprisingly low. The typical American family with a household head age 60 to 65 has very little retirement saving, with median liquid wealth equal to about $\$ 6600$ (Venti and Wise [1992]). Lumsdaine and Wise [1994] document various components of elderly wealth and labor force participation and discuss their interaction. Auerbach, Kotlikoff, and Weil [1992] note that the incomes of the elderly are becoming increasingly annuitized as a result of increases in pension benefits and Social Security during the early 1980s. They note that the fraction of elderly income attributable to these two sources rose from $40 \%$ in 1967 to $55 \%$ in 1988 , a $37 \%$ increase. With increased annuitization, it is possible that retirement income planning will become easier by reducing future uncertainty. However, it is not the fraction of annuitization that is important in the context of adequacy, but the amount. 
There is additional evidence that the elderly will continue to find themselves with inadequate income to carry them through retirement. The American Society of Pension Actuaries (ASPA) found that employees receive only limited investment advice when it comes to retirement planning. What advice is given often occurs within one or two years of retirement. The ASPA recommends four vehicles with which to improve one's retirement income. At the individual level, income is expected to come from personal savings, Social Security, pension, and supplemental work after retirement. At the macro level, they emphasize a need for universal coverage and replacement rates targeted as high as $85 \%$ of final pay for low income workers, $73 \%$ for higher income workers. In 1990 , average replacement rates for Social Security varied from $28 \%$ for maximum earners to $56 \%$ for low-wage earners. Currently only $12 \%$ of employers surveyed have pension plans that are designed around specific replacement rate goals. In addition, of those that do have specific replacement rate goals, the target replacement rate falls far short of those recommended by the ASPA (Employee Benefit Plan Review, [March 1994]). Figure 4 shows average replacement rates for defined benefit (DB) plan participants in 1989. Evidence in Mitchell [1992] concurs; for representative workers in DB plans with 30 years of service, replacement rates ranged from $34.6 \%$ for individuals with final earnings of $\$ 15,000$ to $29.8 \%$ for an individual with final earnings of $\$ 40,000$. Fewer years of service substantially lowered replacement rates at all levels; for example, a worker with only 10 years of service could expect a maximum replacement rate of $12.1 \%$. According to reports in Employee Benefit Plan Review [June 1994], using the Consumer Expenditure Survey, replacement rates for lower income individuals in 1993 were nearly the same as in 1988; the replacement rates for higher income individuals had gone up dramatically.

Of particular concern is the adequacy of retirement income for women (for a review of the literature, see Weaver [1994]). While the proportion of elderly living alone is expected to remain constant in the future, the percentage that are women is projected to increase, as seen in Figure 5. In addition to having longer life expectancies, women have traditionally been more likely to experience gaps in service, leading to reduced Social Security and pension benefits. As more women enter the labor force, concern over 
adequacy of retirement income for women may decrease. In 1959, $40 \%$ of women above age 16 were in the labor force, compared with $60 \%$ in 1989 (US Department of Labor [1992]). Additional evidence suggests improvements in earnings which will lead to higher Social Security benefits. Over roughly the same time period, the percentage of women over 62 receiving Social Security benefits on the basis of their own work history has increased from $43.3 \%$ to $59.7 \%$ (see Table 3 ). It is not clear that there have been similar improvements in pension benefits. Even and MacPherson [1994] note that "pension coverage for women is less likely to convert into pension receipt at retirement." They also find that men are "two to three times more likely to receive pension income than females." In addition, the average level of benefits for women is between 55 and 62 percent of the average level of benefits for men. Even and Macpherson estimate that one-third of the gap in coverage between men and women is attributable to women's absence from the labor force (their work history). Some of the policies that have been proposed to address this disparity are earnings sharing, homemaker credits, and caregiving credits (Employee Benefit Plan Review [March 1994], from Ferber [1993]).

While an obvious solution to the threat of inadequate retirement income is a shortened retirement phase (either through prolonged work, delayed retirement, or earlier mortality), trends in labor force participation and life expectancies both suggest that retirement savings will need to be stretched over more years of life rather than fewer. Labor force participation rates of the elderly are decreasing, particularly among men. Table 1 compares labor force participation rates of men and women at various ages between 1970 and 1990. While male labor force participation rates have decreased dramatically, corresponding rates for women have increased in the first three groups, while declining for women in the 62-64 and 65+ age groups. As a result, the gap between male and female labor force participation has narrowed over the last 2 decades, by about 15 percentage points for those aged 50-62 (Perrachi and Welch [1994]). In addition, the modal labor force participation transition age has moved from 65 in 1968 to 62 in 1991 (Quinn and Burkhauser, [1992], Perrachi and Welch [1994]). 
In addition to declining labor force participation trends, life expectancies are also increasing. Table 2 shows life expectancies and projections for white men and women under three different demographic scenarios (these are described in Hurd [1994b]). In the last decade, the life expectancy for men has increased by one year. Depending on the projection used, even scheduled increases in the Social Security eligibility age, aimed at encouraging later retirement, will not keep up with the increasing life expectancies. The elderly population is itself aging. In $1980,40 \%$ of individuals $65+$ were over age 75 . By 2000 , this proportion is expected to have risen to $50 \%$. As individuals age, the threat of poverty rises substantially. In 1990 , one-fifth of persons age 85 or older had income levels at or below the poverty threshold (Radner [1993b]).

Because of these trends, the ratio of the retired population to the working population is expected to rise from 0.21 in 1990 to 0.27 in 2020 to 0.37 in 2035 (Congressional Budget Office (CBO) [1993]). The number of Social Security beneficiaries has also increased dramatically, as shown in Figure 3. To remain solvent, the current Social Security system will have to impose an increasingly large tax burden on the shrinking working population in order to support the growing elderly population.

\section{Social Security}

In 1990 , nearly $40 \%$ of the income of the elderly (65+) was from Social Security (Congressional Budget Office [1993]). In addition, $57 \%$ of the elderly obtained more than half their income from Social Security; $24 \%$ obtained more than $90 \%$ from this source (Hurd, [1994a]). Almost 95\% of elderly households reported receiving Social Security benefits (Hurd [1994a] and Congressional Budget Office [1993]); these benefits are an especially important component of income for households in the lower income brackets and are the largest single source of income for all but the highest income quintile of elderly (Reno [1993]). It is projected that for retirees in the bottom half of the income distribution in 2019, 60-70 percent of their retirement income will come from Social Security (Kingson [1992]). As a result of pressures on the Social Security system and rising health care costs, concern that the income of the elderly will be inadequate has 
created debate over how to increase retirement income, accompanied by legislation aimed at effecting such an increase.

Because Social Security affects so much of the elderly population, it is the obvious place to start in discussing broad based policy changes that influence retirement behavior and income. Previous research considering the effects of changes in Social Security policy on retirement and labor force participation includes Gustman and Steinmeier [1991] and Feldstein and Samwick [1992]. Referring back to Table 1, it is clear that labor force participation rates decline precipitously among individuals that have reached the Social Security early and normal retirement ages (62 and 65, respectively). Using aggregate time series data, Stewart [1995] provides further evidence of the influence of Social Security, demonstrating that ratios of PIA/earnings closely mirror the non-participation rate of men ages 65 and older, as shown in Figure 6. However, evidence in Bondar [1993] suggests that individuals with high pre-retirement earnings (as estimated based on PIA amount) are most likely to continue to work and earn high post-retirement earnings. In addition, replacement rates (PIA/earnings) are higher for low-wage individuals, suggesting that the labor force participation decline is being driven by precisely the individuals for whom concerns over retirement income adequacy are the largest. Therefore, discussions regarding the government's role in ensuring adequacy of retirement income have focussed on the Social Security program and its ability to meet the needs of a growing elderly population.

Researchers also have become increasingly aware of the Social Security system's inability to accurately provide for many women in their retirement. This is partly due to the societal norms under which the system was designed (i.e., around the "traditional" one-earner family) and to differences in men and women's labor force history and attachment. Ferber [1993] provides evidence that the earnings gap, along with male/female differences in labor force participation and tenure, has declined, but not disappeared.

In order to increase labor force participation and decrease the burden on the Social Security system, current Social Security policy dictates an increase in the normal retire- 
ment age from 65-67. Those born in 1937 were the last group with the normal retirement age at 65 . Those born in 1960 will be the first with the normal retirement age at 67. Many believe that this increase is too gradual. In addition, the level of benefit reduction at age 62 will gradually increase from 80 percent to 70 percent. The earnings test will be liberalized; it currently only affects individuals below age 70 . To try to reduce some of the perceived inadequacies of the Social Security system, an earnings-sharing proposal (where the Social Security benefit is based on the earnings of the household, not just on individuals) and a two part payment system have also been suggested. The latter is an attempt to meet the dual roles of the Social Security system - to provide a basic amount of coverage to all elderly (not just wage earners and their spouses), and to provide an additional payment proportional to wages. As mentioned earlier, additional proposals include caregiving and homemaker credits, but the current design (of supporting wage earners in retirement based on revenues from current wage earners) does not suggest an obvious answer to the question of who will pay for such credits. ${ }^{1}$

The earnings test component of Social Security, which applies to individuals below age 70 (the age limit was 72 prior to 1983 ), is viewed as a significant barrier to continued work. In addition, the earnings test is more liberal for Social Security recipients above age 65 than for those aged 62-64. In 1990, the benefit reduction rate was decreased for individuals 65 and over from $1 / 2$ to $1 / 3$. That is, for individuals aged $62-64$, for every $\$ 2$ of earnings above the maximum allowable limit, an individual's Social Security benefit is reduced by $\$ 1$, while the same reduction is applied to every $\$ 3$ of earnings for those age 65 and over.

Bondar [1993] studies individuals affected by the earnings test in 1989. Among Social Security beneficiaries, $75 \%$ were retired workers, $36 \%$ of these had their entire benefit withheld. He notes that in addition to Social Security beneficiaries, there is a potentially large group of individuals who are discouraged from applying for Social Security benefits because they know their benefits will be withheld. This latter group is unobservable and

1 For more discussion on these topics, see Ferber [1993]. 
therefore limits the accuracy with which predictions about potential policy changes can be made. It is estimated that approximately $40 \%$ of insured men and women age 62-64 do not file for benefits, between $5-15 \%$ (for men and women, respectively) of those age $65+$ do not.

Honig and Reimers [1989] argue that the returns to eliminating the earnings test are decreasing with the proliferation of private pensions, which often encourage individuals to withdraw completely from the labor force. This suggests that in modelling the impact of Social Security policy, it is important to include private pensions, as omitting this crucial interaction may prove misleading. Evidence of this is also given in Stock and Wise [1990b] and Lumsdaine, Stock, and Wise [1994b], who demonstrate via simulation, using data from two individual Fortune 500 firms, that for individuals with pension plan availability, changes in Social Security policy will have very little effect. They attribute this to the relative magnitudes of pension versus Social Security benefits. However, for individuals that rely solely on Social Security, changes will have a much larger effect. In addition, Lumsdaine, Stock, and Wise [1994b] show that even for individuals in their firm, who have access to both a pension plan and Social Security, the complete elimination of Social Security would significantly impact labor supply behavior.

Leonesio [1993a], in summarizing the literature and findings regarding the Social Security earnings test, concludes that "...research suggests that retirement decisions are influenced by the availability and generosity of Social Security and private pensions, health status, job characteristics, wage offers, family circumstances, and personal preferences for work versus leisure time. These other contributing factors that encourage or enable retirement appear to be dominant."

In order to promote continued work and to offset partially the effect of the earnings test for workers age 65 to 69 , the delayed retirement credit (DRC - the amount added to one's annual Social Security benefit to take into account non-receipt in previous months, either due to the earnings test or postponement of application) has increased over the last decade, from $1 \%$ to $3 \%$ in 1983 , and to $4 \%$ in 1989 . It will continue to increase by 
$.5 \%$ every other year until reaching a maximum of $8 \%$ in 2010 , with the age past which it is applied increasing as the normal retirement age increases. This is designed to be approximately actuarially fair using current mortality probabilities. While this is an alternative to the relaxation of the earnings test, it may achieve similar results, benefitting more those with higher benefits (earnings). In terms of behavioral impact, however, the two may differ substantially depending on the structure of individual preferences (see Honig and Reimers [1989], footnote 1). Whether or not this policy will succeed in its goal to eliminate the cost associated with continuing to work depends on assumptions about the future, both at a macroeconomic level (e.g., the stability of tax rates) and at a microeconomic level (e.g., individual earnings profiles).

Research seems to suggest that the labor supply impact of these liberalizations will not be substantial (Gustman and Steinmeier [1991], Leonesio [1990]). Gustman and Steinmeier [1991] conduct a simulation study using the Survey of Consumer Finances (SCF) to assess the impact of changing the DRC from $3 \%$ to $8 \%$ and of eliminating the earnings test. The SCF has the advantage of also containing information about pension plans. Gustman and Steinmeier incorporate many details such as pensions that other studies omit and include a number of stochastic terms representing such things as health status. Their results suggest that the impact on labor supply would be modest, increasing labor force participation by about 3.5\% per year for individuals age 65-69. In particular, the average date of retirement would increase by about three weeks. In addition, they argue that this is because individuals will adjust to policy changes by altering their time of application for benefits rather than modifying their labor supply behavior. In addition, they argue that no single DRC is appropriate for all individuals.

Mitchell [1989] considers four changes in the Social Security benefit formulas: 1) raising the normal retirement age, 2) delaying the cost-of-living adjustment, 3) increasing the DRC, and 4) increasing the penalty for early retirement. All four of these are intended to increase labor force participation and delay retirement and are representative of policy currently being implemented. Mitchell [1989] simulates the retirement response to these changes via a logit model. Despite drastic changes in benefit amounts, the predicted 
impact of an increased penalty for early retirement is modest; retirement for men is delayed by three months. The other simulations yield smaller results; these findings are consistent with those of Gustman and Steinmeier [1991] and Lumsdaine, Stock, and Wise [1992, 1993]. For women, the impacts are even less pronounced. Using time series data, Stewart [1995] predicts a much larger effect than previous studies based on microdata of changes in Social Security provisions. In particular, he attributes nearly $40 \%$ of the decline in labor force participation rates to Social Security. Of the four changes considered, Mitchell finds it is the final change that contains the most powerful financial incentives to alter labor supply behavior. Stewart [1995] concurs, sighting liquidity constraints as the reason why many individuals wait to exit the labor force until after reaching the Social Security early retirement age. Increasing the penalty for early retirement will cause more individuals to be liquidity constrained and therefore unable to finance an exit from the labor force. In particular, there is evidence that such changes will have a substantial effect on the fraction of elderly families at or near the poverty level, precisely those that are likely to be liquidity constrained. In $1988,68 \%$ of new retired worker Social Security awards for men ( $74 \%$ for women) were made prior to the normal retirement age (Kingson [1992]); it is therefore unlikely that changes to this later age would have substantial effects on retirement behavior.

Leonesio [1993b] describes other Social Security policies that have been proposed in an attempt to encourage prolonged work by the elderly. His conclusion is that "changes in Social Security programs of the type and magnitude that are politically feasible in the foreseeable future are unlikely to produce large changes in retirement patterns." This brings into question the expenditure invested in examining Social Security policy. Perhaps the focus should be in areas thought to have greater effects. In documenting previous results by a variety of researchers (e.g., Burtless and Moffitt [1984, 1985], Fields and Mitchell [1984]), he notes that the effects of increases in monthly benefit levels tend to be modest; a $10 \%$ increase (decrease) is associated with a corresponding increase (decrease) of the retirement age by about one month. In fact, the effects of all policy changes he reviews are described in terms of months, not years. He argues, however, 
that this is because it is also necessary to examine the effects of Social Security policy changes on related decisions that may affect the retirement decision.

While much of the literature on Social Security (and retirement behavior more generally) has used reduced form models, which can document correlations and explanatory power, structural models are important for assessing potential policy impacts. As noted by Rust [1989], early research on Social Security used a life cycle consumption model, which, in its simplest form, predicts that individuals will decumulate their wealth towards the end of their lives. This is contrary to observations on savings behavior of the elderly. However, a more general life cycle model, with rigidities such as liquidity constraints or a bequest motive, provides a dynamic context in which to model behavior. Rust formulates a dynamic programming model where workers use an optimal decision rule to choose their retirement date. The control variables are consumption expenditures and the decision regarding retirement; the model allows for uncertainty in the state variables, which are things like life expectancy, health status, and retirement earnings. One of the elements missing from Rust [1989]'s model is pension benefits. This is due to data limitations in the Retirement History Survey; such limitations will be less apparent in the new Health and Retirement Survey.

Despite significant research devoted to the impact of Social Security provisions, debate still continues as to the relative importance of Social Security on the retirement decision and retirement income. Part of the difficulty lies in attempts to predict responses in a heterogeneous population. Inferences depend crucially on the sample studied and on additional factors and sources of income. There is also disagreement regarding the validity and accuracy of using reduced-form models to predict the effects of policy changes, and, even among structural models, static and dynamic approaches can result in very different predictions.

\section{Pensions and Window Plans}

What can be done to assist the projected shortfall in Social Security? One solution is to rely on pensions for supplemental income. Income from pensions accounts for about 
$18 \%$ of all income of elderly $(65+)$. The proportion of elderly households receiving income from all types of pensions in 1990 was $44 \%$ (Congressional Budget Office [1993]). This proportion and its relative importance varies considerably along demographic lines. For example, while $57 \%$ of elderly couples age 65 and older report receiving a pension, only $32 \%$ of unmarried women do (Reno [1993]). It is projected that for those in the upper half of the retirement income distribution in 2019, 30-40\% of cash income will come from private pension benefits (Kingson [1992], citing a CBO projection). Two-thirds of individuals in the Health and Retirement Survey (HRS) report having pension coverage (Gustman, Mitchell, and Steinmeier [1994]). Of these $42 \%$ have only DB plans, while $16 \%$ have only DC. It is becoming increasingly common for employees to face a number of choices regarding pension plan and saving for retirement. According to a survey by Merrill Lynch, as reported in the Employee Benefit Plan Review [June 1994], "only 61\% of preretirees have savings and investments apart from an employer-sponsored pension plan."

Reimers and Honig [1992] cite difficulties in inference on labor supply behavior with nationally representative data due to a lack of detailed pension plan information. This is particularly important when analyzing the behavior of men, for whom pension benefits are a greater proportion of retirement income. "The lack of pension information means not only that one cannot estimate the effect of pensions, but also that one cannot obtain unbiased estimates of the effects of other variables."

It has also been shown that pension plans can be a useful tool with which firms can affect workers' behavior. Clark, Gohmann, and McDermed [1988] note that defined benefit plans in particular provide incentives for employees to remain at a specific firm and to refrain from behavior that might lead to their dismissal. They note that "firms with high costs of hiring and high monitoring costs also will tend to use defined benefit plans." In addition, firms can use defined benefit plans to alter retirement behavior. Ruhm [1994] provides evidence that pension coverage is associated with increased attachment to the labor force through certain ages, followed by decreased probability of attachment at later ages. 
Lumsdaine, Stock, and Wise [1992] use data from a single Fortune 500 firm to illustrate the dangers of drawing inference without pension information for individuals that, in fact, have access to a pension plan. In simulating the effects of eliminating Social Security early retirement using information on both types of retirement income, they estimate between a 9 and $15 \%$ reduction in retirement rates of individuals ages 62-65; without incorporating pension information, the reduction would be estimated to be between 43 and $72 \%$. In addition, the interaction between Social Security and pension plan provisions is well-documented - the General Accounting Office (GAO) [1989] estimates that $42 \%$ of pension plans used some method of integration in computing benefits.

While pension coverage rates have remained reasonably stable over the last 20 years (Table 4, see USDoL [1994]), the percentage of pension-covered workers enrolled in primary DB plans has declined dramatically, from $87 \%$ in 1975 to $68 \%$ in 1987 (Ruhm [1994] cites Beller and Lawrence [1992]). Clark, Gohmann and McDermed [1988] argue that in response to increased pension regulation, and legislation, the 1980s have seen a shift from DB to DC pension plans. Reno [1993] notes that this shift accounts for only $10 \%$ of the growth in primary DC coverage; the majority of the growth is due to new plans, both primary and supplemental. DB plans are often based on final salary (or average of final few years) and take the responsibility of saving for retirement away from the individual. To the extent that individuals fail to save adequately for their retirement, this may not be a negative characteristic. In a survey of 944 major US employers, $96 \%$ of DB plans did not require employee contributions (Hewitt Associates [1990]). Even firms that have a DB plan as their primary plan often offer a DC plan to supplement the primary plan. DC plans often allow for more mobility than DB plans. Particularly popular are 401(k) plans, where the employee shares in the responsibility for his/her retirement income by contributing jointly with the employer. By 1987 , they were primary plans for $8 \%$ of private plan participants - supplemental for an additional 23\% (Reno [1993] cites Beller and Lawrence [1992]). An additional attractive feature is the availability for the employee to make supplemental voluntary tax-deferred contributions (Reno [1993]). The 
observed increase in DC plans means increased portability. "Without portability, the average private pension participant receives benefits $15 \%$ lower than if all benefits were fully portable" (Kingson [1992]). However, there is also evidence that portable benefits are often received as a lump sum; this option undermines the security such plans are intended to provide. Prior to receipt of the pension distribution, the risk of investment performance of the pension funds in DC plans is borne by the employee. In addition, recipients are able to use distributions for other purposes (Woods [1993]). Reno [1993] notes that in 1988 , only $11 \%$ of workers with previous lump-sum distributions reported rolling it all into a tax-deferred retirement account.

Private pension plan provision policy changes have occurred in a variety of ways, from the extreme form of liquidation of the existing company plan ${ }^{2}$ to special "window" (incentive) plans targeted at a particular group of workers. Such plans have sometimes accompanied a restructuring or downsizing of the firm and have tended to be fairly generous. As a result, these plans, which often target a specific group of workers and provide special incentives to retire (leave the firm), have a profound effect on the labor force participation rates of the target group.

\section{A. Literature Review and Previous Methodology}

Much of the literature on pension plans and retirement is based on results using static models. These include least squares models as well as limited dependent variable specifications (e.g., Clark, Gohmann, and McDermed [1988], using plan choice (DB or DC) as the dependent variable, Lumsdaine, Stock, and Wise [1992] and Samwick [1993], using retirement as the dichotomous dependent variable, Even and Macpherson [1994], using coverage as the dependent variable, Haveman, deJong, and Wolfe [1991], using labor market participation as the dependent variable, Gustman and Steinmeier [1993b], using job separation as the dependent variable), median regression (Samwick [1993]), and proportional hazard models. These models have systematically documented the effects

2 From 1985-1988, there were 3.3 million participants in DB plans that were terminated (Beller and Lawrence [1992]). 
of pension plan provisions on the retirement decision and retirement income. They have been less successful in predicting the effects of a change in policy.

Gustman and Steinmeier [1993b] address the notion that pension plans reduce labor mobility (create "job lock"). Using separation as the dependent variable in a reduced form probit model, they find that pension plans are not a substitute for wage compensation; instead compensation in pension covered jobs is higher. The "compensation premium" accounts for increased attachment to the firm, rather than the non-portability of pension plans. DC plans, which are more portable, exhibit similar effects on mobility.

Allen, Clark, and McDermed [1993] note that the observed lower mobility among pension covered workers may be due to both a bonding effect (as noted by Gustman and Steinmeier [1993b]) and a sorting effect, that workers with certain observable characteristics prefer pension jobs. ${ }^{3}$ They find evidence of "self-selection of workers with low odds of turnover into jobs covered by pensions." Understanding and modelling such selection issues is critical to interpreting and predicting the impact of changes to pension plans.

A careful review of pension legislation over the last decade is in Clark, Gohmann, and McDermed [1988], who use a probit model with plan choice as the dependent variable to consider the impact of regulation on a firm's choice of pension plan type. They find that the probability of a firm offering at least one DB plan has declined throughout the last decade. The shift towards DC plans as a result of favorable tax treatments and anti-age-discrimination regulation is indicative of the way that firms can respond to government legislation. This casts doubt on the efficacy of government plans to alter the labor force composition via Social Security changes; Lumsdaine, Stock, and Wise and others have argued that firms may well offset potential effects via their pension plans.

Luzadis and Mitchell [1990] also find that the regulatory environment has significant impact on employer-sponsored pension incentives, most noticeably with regard to Social

3 Or they agree to engage in the implicit labor contract that is offered. For theories of pension plans, see, for example, Ippolito [1985], Kotlikoff and Wise [1985], Viscusi [1985], and Lazear and Moore [1988]. 
Security policy changes. There is also evidence that the observed dynamics pertain to the "buyout" hypothesis, that firms encourage certain individuals to leave. Both of these findings emphasize that response to pension plan provisions should be modelled in a dynamic context, which acknowledges the flexibility employers have to manipulate plan characteristics and incentives.

A number of models have been used to capture more of the dynamic decision process of individuals. Such dynamic models are critical to understanding actual behavior. The benefit of dynamic behavioral models is the potential for policy analysis. The model's parameters can be estimated under a base case scenario and a variety of dynamic policies can be assessed. Unfortunately, exactly modelling such dynamics in a way that mirrors reality is difficult, if not impossible. It is therefore necessary to make simplifying assumptions in order to achieve tractability. In addition, there is debate as to what the goal of mirroring reality seeks to accomplish - do we want to imitate the decision making process, or are we satisfied with achieving similar outcomes and the ability to accurately predict future outcomes?

Gustman and Steinmeier [1986] ignore uncertainty and assume perfect markets in constructing a life-cycle model of retirement. The model specifies reduced wages for diminished work effort. They use the Retirement History Survey (RHS) dataset and maximum likelihood estimation. They note that the peaks at age 62 and 65 in retirement rates are completely attributable to Social Security, pension provisions, and mandatory retirement. Simulations implementing the shift of the Social Security normal retirement age to 67 produce a corresponding shift in the latter peak in retirement rates.

Stock and Wise [1990a,b] proposed the "option value" model, where individuals retire at the age that achieves the maximum gain from postponing retirement versus retiring in the current period. The motivation for their model is from Lazear [1979], which suggests that by delaying retirement, individuals retain the option to retire at a later date, under potentially more advantageous terms. In the Stock-Wise model, individuals re-assess their options at each new time period. The model is fairly flexible 
in that it allows for correlated individual-specific errors and features a parsimonious specification. Correlated errors in a dynamic setting are difficult to model analytically, as the model would involve high orders of integration. The tractible simplification, in this case, is that individuals maximize the present discounted value of expected wealth. ${ }^{4}$ In addition, a parameter is included to take into account the possibility that an individual values a dollar associated with work differently from a dollar associated with leisure. Stock and Wise use data from a single Fortune 500 firm. These data consist of a panel of individual earnings histories over a number of years. In addition, the data are well-suited for analyzing the validity of the model; parameter estimates can be obtained using data from one year and used to predict behavior in subsequent years. The results of such an analysis, as well as the incorporation of individual-specific errors that follow an $\operatorname{AR}(1)$ process, are in Stock and Wise [1990a].

Stock and Wise [1990b] also consider a number of simulations to assess the effects of potential policy changes. Using the parameters obtained under the base specification, they simulate the effects of increasing the firm early retirement age, increasing the Social Security early retirement reduction factor, and increasing the Social Security early retirement age. Subsequent papers by Lumsdaine, Stock, and Wise (LSW) [1990, 1994a] have considered modifications to the base model.

Lumsdaine, Stock and Wise [1992] compare a simpler, static model (probit), two dynamic programming models with uncorrelated individual-specific errors, and the option value model. They find that the three dynamic models perform significantly better in terms of fit and prediction than do static probit models. A separate issue, raised by LSW [1992], is what the goal should be with these increasingly complex models (see also Burtless [1989]). There are clear gains in inference from using dynamic models over the static ones. If the goal is to mirror the observed pattern of behavior, these models

4 In a true dynamic programming framework, individuals choose the expected maximum given a variety of choices in each time period. Thus the approximation in the StockWise model induces a bias towards early retirement (Emax $>$ maxE from Jensen's Inequality). 
do quite well. However, it also may be desirable to mimic the actual decision-making process that an individual undergoes. In this case, it is hardly plausible that the average individual will utilize the level of complexity specified in these dynamic models. In addition, usually the more complicated the model, the more simplifying assumptions necessary to retain tractability. It is therefore necessary to ensure that models are robust to misspecification and to determine the impact of these assumptions and their relation to actual behavior.

LSW [1994a] compares the behavior of men and women. Contrary to common belief, for individuals in the specific firm they consider, the actual behavior is quite similar; this is also reflected in the parameter estimates and the predicted behavior. Because there are only 2 transition states, maximum likelihood is feasible; a modified simulated annealing (random search method, not requiring second or even first derivatives of the relevant function) is employed at times in estimation. Dynamic models that allow for multiple choices (transition states) usually need to employ integral approximation techniques to retain tractability.

Window plans, when analyzed with corresponding individual firm pension details, provide a convenient way to test a model out-of-sample; the model is estimated under the normal pension provisions, then the estimates are used to predict the effects of the window plan. Lumsdaine, Stock, and Wise $[1990,1991]$ evaluate the effect of a window plan in the same Fortune 500 firm that Stock and Wise [1990a,b] considered. LSW [1991] finds that the predicted effects typically match the actual effects well, the notable exception being at age 65 , where the models always underpredict the retirement effect. LSW [1990] uses a beta distribution to approximate the firm's pension plan in order to investigate whether the firm could have more effeciently achieved its potential goals. A beta distribution provides a parsimonious flexible functional form which allows the pension schedule to vary continuously (thus providing determination of exact schedules without being bound by discretization). They then consider potential motivations that the firm may have had for offering a window plan, based on economic theory, and investigate whether the firm could have structured its plan more efficiently, subject to the 
budgetary restrictions that it faced. If the main motivation was to reduce immediately the current size of its labor force, the firm acted close to optimally.

In a more recent paper, Lumsdaine, Stock, and Wise [1994b] simulate the effects of a number of different policy changes, using data from another Fortune 500 firm. Besides confirming, using this alternative dataset, their earlier results, they investigate the effects on labor force participation of changes in the Social Security early and normal retirement ages, the private pension plan provisions, the interaction of changes in both Social Security and pensions, retiree health insurance, forced reductions in work load, and other policies.

The evidence associated with this body of literature is relatively clear. For those people who will receive pension benefits, the magnitude of the expected benefit is such that pension plan provisions can strongly influence their retirement decision.

\section{B. What We Would Like to Know}

An important aspect to modelling the determinants of retirement behavior and retirement income is understanding how Social Security and pensions interact with other forms of retirement savings. In particular, do they provide additional savings or are they substitutes for alternative forms? Much of the research has focused on shortfalls in retirement income or benefit levels for individual retirees. From a macroeconomic perspective, it is important (Day [1993]) to assess the tradeoff between generations as part of the cost/benefit analysis. Day cites overwhelming support across all ages for maintaining or increasing Social Security benefit levels, but suggests that younger workers may not completely understand how these levels would be raised. Attitudes towards taxes and attitudes towards benefits are only weakly correlated. Day claims this is because attitudes towards taxes are more likely to be driven by self-interest whereas attitudes towards benefits are more ideological in nature.

Another significant source of uncertainty is how firms will react to changing labor force participation and needs. Will they support government policy to encourage older 
workers to continue working, or will they try to counterbalance the Social Security effects via manipulation of their pension plan provisions? The upward-sloping wage curve makes it difficult for firms to retain older workers in a cost-effective way. In addition, anecdotal evidence of firms rehiring retirees that have opted for a window plan, often at higher consulting wages, suggests that firms have difficulty convincing the "right" (less-productive) people to retire; a more systematic assessment of firm behavior would provide insight as to the frequency with which this occurs. Note that economic theory would predict that workers with a high opportunity cost of leaving (those that would have difficulty finding an equivalent job) would be less likely to accept a window plan. The results of Lumsdaine, Stock, and Wise [1991] are not inconsistent with this theory and anecdotal evidence; they do, however, suggest that firms may be operating under rather myopic, short-term objectives (such as paring down the size of its labor force, without regard to overall productivity or future productivity) when offering window plans.

It is also clear that individuals do not always have an accurate perception of the components of their expected retirement income. A study by Merrill Lynch (as reported in Employee Benefit Plan Review, [June 1994]) found that of individuals ages 45-64, $36 \%$ cited pensions as their expected most important source of retirement income. In reality, only $10 \%$ of income comes from pensions, according to a United States Department of Health and Human Services report (Radner [1993a]). A poll by the Employee Benefit Research Institute (EBRI) found that nearly half of all respondents believed that $\$ 150,000$ or less was what they needed in order to fund their retirement. In addition, only one-third of individuals correctly chose the range of dollar amounts that included the maximum Social Security benefit when given four choices. Additional evidence of inaccurate understanding by elderly regarding the Social Security earnings test rules is found in Leonesio [1993b].

While much of the literature on pensions has focussed on coverage, in considering individuals most at risk in terms of potential future income inadequacy, it is important to consider pension receipt and not pension coverage. Gender differences in pension coverage become even more pronounced when measuring receipt; women are much more 
likely to experience interruptions in labor force attachment and thus are less likely to meet vesting requirements in a pension plan than men. ${ }^{5}$ In 1992, median income from private pensions for male recipients was approximately twice that of female recipients, at all 5-year age intervals for individuals above age 65 (Grad [1994]). Controlling for tenure, coverage rates are fairly similar, as shown in Table 5 . Another reason that women are particularly at risk is due to the earnings gap. The coverage rates for men and women are very similar at similar earnings levels; disparity arises due to the concentration of women in the lower part of the earnings distribution, as shown in Table 6. Multiple vesting further increases the gender gap. Among men age 50-59 who were working fulltime in $1988,15 \%$ were vested in a previous job ( $24 \%$ of workers age 60 and older) while among women in both age groups only $5-6 \%$ were so vested (Woods [1993]).

There is some evidence that for women, pension coverage is associated with increased attachment to the labor force in later life (Pienta, Burr, and Mutchler [1993]). Possible explanations for this counterintuitive observation include a selection effect and the need to make up for an earlier discontinuous work history in terms of vesting and the earnings gap. This explanation is supported by evidence in Ruhm [1994], who finds that for men in the RHS, late entry into a pension covered job is associated with increased attachment to the labor force, even more than for non-pension-covered individuals.

In addition, pension coverage may be leveling off (recall Table 4). Quinn, Burkhauser, and Myers [1990] suggest that if increasing pension coverage is responsible for the observed trend towards early retirement, a levelling off of coverage may signal a corresponding increase in average retirement ages relative to current projections. DC participants seem to comprise $1 / 3$ of all pension participants, as compared with $1 / 6$ fifteen years earlier. In addition, more employers are offering supplementary coverage; this is most often in the form of a DC plan. The proliferation of these plans also suggests that the incentives to retire early, usually associated with DB plans, are weakening. However,

${ }^{5}$ Woods [1993] notes that "while the gender gap is relatively small among workers under the age of 40 , it diverges sharply among older workers". 
DB plans are relaxing their requirements for receipt of benefits; see the sources cited in Quinn and Burkhauser [1992] for evidence that this promotes early retirement.

Much of the literature has used large aggregate datasets to investigate the influence of pension plans on the retirement decision. The advantage of using large datasets is that they may be more representative of the population and therefore more useful for policy evaluation. The disadvantage is the loss of heterogeneity which typically arises from the absense of details of each individual pension plan. In order to control for some of this heterogeneity, Stock and Wise [1990a,b] use data from one particular Fortune 500 firm. The size of the firm allows for an adequate sample while providing a level of detail regarding the pension plan provisions that is not found in more aggregate datasets.

The obvious benefit to using data from a single firm is the use of detailed pension plan information and earnings records. However, such an approach is not necessarily representative of the aggregate population. An important research priority should be the availability of better earnings records, in a more timely manner, while still maintaining confidentiality. Data on Social Security earnings records would provide an entire wage history for each individual; tax data from the IRS would supplement this with information on additional assets, which are critical for evaluating the adequacy of retirement income and savings. While some information would still have to be imputed (e.g., expected future levels), the level of imputation would be much more accurate than what is currently available; imputations from aggregate data do not effectively capture the heterogeneity in the population.

More recent datasets, such as the HRS, link extensive survey responses on work history, health status, and assets to pension plan detail from the individual's specific firm. This provides hope of estimating more dynamic models using broader based studies that are more representive of the population. In addition, evidence in Hurd and McGarry [1993b] suggests that workers' subjective probabilities of working past ages 62 and 65 reflect details of their pension plan provisions. In particular, the probability of working past age 65 for individuals with no pension plan is more than double the corresponding 
probability among workers with pension plans that allow for full benefits by age 62 . Additional subjective questions, such as how much benefits are expected to be, will, in future years, be matched up to actual receipt in order to draw inferences regarding expectations. The HRS also asks what form the benefit is expected to be received in (i.e., lump sum, annuity, etc.). Many other subjective questions about work and perceptions of and interactions with things related to work are also asked, along with additional information regarding early retirement window plans.

It is important to emphasize that, while many researchers have noted the significant effect of pension plan provisions and have estimated this effect to be much larger than the one associated with changes in Social Security provisions, for the fraction of the population that relies solely on Social Security benefits, changes to Social Security will, in contrast, have a profound effect. This is discussed in Hurd [1994b] and Lumsdaine, Stock, and Wise [1994b]. Pension benefits are thought to be of more importance when considering the relative magnitudes of actual benefits for individuals that have them; Social Security benefits may be more important when assessing the aggregate (or even the median) impact of policy changes.

It has been documented (Kotlikoff and Wise [1985, 1987]) that pension plans, particularly DB plans, have incentive effects by which firms can manipulate the composition of their employees. Federal regulations have sought to limit these incentive effects (Clark, Gohmann, and McDermed [1988]). For example, the Age Discrimination in Employment Act (ADEA) protected older workers from the threat of mandatory retirement. Quadagno and Hardy [1991] argue that "private firms developed extensive early retirement packages that provided incentives for early retirement and disincentives for continued employment."

The recessions of $1973-4$ and $1981-2$ provided additional inducements for firms to offer early retirement programs; window plans allowed firms to target a specific group of workers for attrition without resorting to layoffs. Window plans were perceived as 
being highly lucrative and beneficial to the employee; firms meanwhile were able to limit future pension liability (Quadagno and Hardy [1991]).

Ironically, while legislation has sought to limit the incentive effects of pension plans, window plans have fallen under less regulation and therefore remain a powerful tool by which firms can seek to influence workers' participation decisions. As their relation to pension plans would suggest, the existence of a window plan, along with to whom it is offered, varies considerably across demographic lines. As anti-discrimination legislation has increased, window plans remain as one of the few ways that employers can legally discriminate among workers (in targetting a specific subset of workers) and over time (historically, as mentioned above, window plans have been prevalent during periods of downsizing). As a result, window plans should continue to be a major policy focus for the next decade.

In addition, as we learn more about individual responses to window plans and how they affect labor force participation decisions, it will be equally important to model firm response and consider whether firms have increased utilization of window plans in light of the more favorable regulatory environment (relative to pensions) or decreased it (due perhaps to the wrong people leaving). Detailed questions about window plans should be included in surveys of firms such as the Survey of Consumer Finances' Pension Provider Supplement and the Bureau of Labor Statistics' Employee Benefits Survey.

Because window plans can vary considerably, studies documenting their effects have focussed on a single window plan. Data regarding window plans are difficult to obtain, as they must be gathered directly from the firm. The HRS is the first survey to contain detailed questions regarding window plans. Analysis of the responses to these questions hopefully will lead to a broader understanding of the magnitude of the individual incentive effects and the potential implications for aggregate impacts on labor force participation.

From a modelling perspective, window plans have offered a unique type of "natural experiment" in the literature of the previous decade. Because there had been no his- 
torical precedent for such alterations to pension plans, initially they were unanticipated. Therefore models could be estimated using pre-window plan provisions and then used to predict the effects of the window plan, in effect creating an out-of-sample test of model predictability. Currently, with the proliferation of window plans among firms and even within the same firm, research methodology requires a change of focus. Models that study the effects of window plans will need to consider how expectations are formulated and incorporated into an individual's retirement decision. Just as the existence of a window plan can induce additional retirements, the absence of one may inhibit retirements if individuals expect one to be offered in the near future. Smith [1994] provides further caveats regarding the interpretation of window plans as an out-of-sample test of the model, citing endogeneity of other factors influencing departure rates, such as the perceived financial condition of the firm. This endogeneity could result in a change in the model parameters, a change which is not captured by the current form of policy simulation.

With focus shifting to issues of solvency of government programs, private sources of retirement income, such as pension plans, as well as individual savings, will become increasingly important. As discussed earlier, Auerbach, Kotlikoff, and Weil [1992] note that the income of the elderly is becoming increasingly annuitized; shifts from DB to DC plans suggest that this trend may not continue. Future research needs to focus not only on the availability of outside sources of retirement income but also on the form of the distribution of this income. With the increase in popularity of DC plans, individuals have more options regarding their distributions and a substantial fraction of individuals elect a lump-sum payment.

Policy in recent years has begun to focus on "preservation" of retirement benefits (Woods [1993]) by enacting legistlation which imposes stiff penalties for failing to roll preretirement distributions into a qualified retirement plan. ${ }^{6}$ Considering pre-retirement

6 In 1986 , a $10 \%$ penalty tax was imposed; this tax was increased to $20 \%$ in 1993 . For this and more details on lump-sum distributions, see Woods [1993]. 
lump-sum distributions, Woods [1993] finds that many of these distributions went to individuals who were either vested or covered but not vested in another pension plan. He argues that there should be less concern regarding potential consumption of a lumpsum distribution for these individuals, especially as such distributions tend to be of fairly small magnitude (the median amount is $\$ 2830$ ). Of the individuals who show no source of additional pension income, Woods finds that many saved or invested the entire distribution, concluding that concern over choice of distribution is of secondary importance to more general concerns over how to increase coverage.

Much of the previous literature has focussed on pre-retirement lump-sum distributions; caution should be exercised in using such results to draw inferences on the adequacy and preservation of post-retirement analogs. Analysis of the HRS will reveal whether pre-retirement patterns of distribution choice and savings reflect post-retirement behavior. The obvious concern is that lump-sum distributions return too much responsibility for retirement saving to the individual; legislation has attempted to enforce the need for adequate retirement-related savings vehicles. Additional research on post-retirement distribution choices is clearly needed.

In terms of modelling, as Gustman and Steinmeier [1986] point out, the use of lifecycle models requires computation of earnings histories. These are often imputed from either self-reported recollections or, in the case of individual firm records, from company records. In the latter case, transitions between jobs are not documented. Stock and Wise $[1990 \mathrm{a}, \mathrm{b}]$ use a $\log$ linear autoregressive wage equation to impute earnings histories and forecast future earnings. Because the time dimension of the panel in their firm was substantially shorter than that used by Stock and Wise, Lumsdaine, Stock, and Wise [1994a,b] use a fixed effects model. In addition, in most of the dynamic models, future wage uncertainty is not allowed. Thus the potential accuracy of our models and our ability to predict the effects of policy changes are limited by our earnings forecasts. Furthermore, other types of uncertainty (such as firm side demand for future labor) and individuals' expectations about them (such as inferences following the announcement of a window plan regarding a firm's financial condition or the probability of a layoff) 
may significantly contribute to an individual's uncertainty. This suggests that future dynamic models may need to incorporate beliefs about changes in the system itself. Such "macro" risks may contribute far greater uncertainty than "idiosyncratic" risks (such as wage uncertainty or health risks). Accurate forecasts of firm response and behavior are critical to understanding what workers will be doing on the supply side of the labor market.

While the models of LSW fit retirement rates well at most ages, they systematically fail to capture the magnitude of the retirement rate at age 65. This underprediction is attributed to "social custom", an interpretation criticized by Rust and Phelan [1993], who argue instead that the cause is the omission of other key considerations, most noticeably, Medicare.

\section{Disability}

There is increasing discussion about the relation between Social Security Disability Insurance (SSDI) and retirement and the possibility that liberalization of disability benefits is partially responsible for declines in labor force participation (see discussion in Rust [1989] and Lewin-VHI [1994]). In addition to the link with retirement, there is also evidence that policy variables influence applications for disability. There is a positive correlation between disability applications and unemployment rates. Others have cited a negative correlation between labor force participation and the generosity of benefits as measured by the replacement ratio (benefits to wages). It seems (Quinn and Burkhauser [1992], Bound and Waidmann [1992], and Waidmann, Bound, and Schoenbaum [1995]) that applications for disability increased over the 1970s and declined in the 1980s. Measuring disability, however, is difficult because some people who are disabled will just choose to retire (or, some people will leave when eligible for retirement when, if they were completely healthy, they would have continued working). Furthermore, disability may result not in complete exit from the labor force but in a reduction in the amount of hours worked. 
Another indication of the link between disability and retirement is that to the extent that individuals are likely to exaggerate their disability conditions, only about half of the rejected applicants return to work (Bound, 1989). One potential reason is that workers filing a disability claim must wait 5 months from the time they leave their jobs in order to receive benefits. In addition, disability benefits, like Social Security benefits, are subject to an earnings test at $\$ 500$ per month. Both of these features inhibit subsequent labor force participation. Some of the literature on this subject suggests an equivalency between the decision to apply for disability benefits and a decision to withdraw from the labor force (e.g., disability is a substitute form of retirement). Indeed, disability benefits convert to retirement benefits at age 65. If policy is aimed at keeping individuals in the work force, the findings of Bound [1989] and Burkhauser, Butler, Kim, and Slotsve [1992] suggest that such efforts should target individuals before they begin the application process.

As mentioned above, the timing of application for disability benefits seems to be correlated with the replacement rate; a higher rate means earlier application on aggregate. In addition, a higher rate is associated with a shorter waiting time before applying after the onset of a health condition (Burkhauser, Butler, Kim, and Slotsve [1992]). Other variables that affect the timing of application include savings and the extent to which the employer could accommodate the disability.

The prevalence of disability among working age persons in the United States is estimated to be between 7 and 14 percent (Lewin-VHI [1994]). This rate has fluctuated over the last three decades, as shown in Table 7. Recent trends in disability insurance have seen a growth in both applications and awards. Much of this is attributable to changes in aggregate macroeconomic variables, such as unemployment. In addition, qualifying rules were liberalized in 1984; this has contributed to the observed growth in awards (Lewin-VHI [1994]). From 1988-1992, applications increased by 29 percent (40\% using the redefined measure of applications, which excludes technical denials and duplicate applicants). Although gender-specific data on applications are not available before 1988 , in $199260.9 \%$ of applicants were male. It is argued that some of the recent 
growth in application (and resulting awards) may be due to demographic trends (e.g., the increase in female LFP, the aging of baby boom cohort). The number of awards over the same time period rose $54 \%$. Similar dramatic growth spurts occurred in the early 1970s. The fraction of SSDI awards to women has risen, most likely as a result of rising applications (in 1992, this fraction was $37 \%$ ). The ratio of awards to applications (the "allowance rate") has fluctuated, in recent years ranging from .29 in 1982 to .49 in 1992. In addition, toward the late 80 s, more individuals were applying concurrently to SSDI and SSI. These applications accounted for between 60 and 69 percent of the growth in applications in 1992; they accounted for about $48 \%$ in 1988. Lewin-VHI [1994] document substantial variation across states in the growth of applications from 19881992. For example, North Dakota had a $4 \%$ increase in concurrent applications; for Rhode Island, the increase was $134 \%$.

The size of the disability insured population has increased as well. "From 1970 to 1992, the average annual growth rate was 1.48 percent for men and a much larger 3.91 percent for women" (Lewin-VHI [1994]). The growth appears to be slowing. The award rate for women is below (roughly $80 \%$ of) the award rate for men. The age-distribution of the adult disability insured population declines with age past age 35, as seen in Figure 7. The percentage of men age 55-64 receiving SSDI benefits has grown from $5.3 \%$ in 1965 to $10.5 \%$ in 1985 (Bound [1989] and Lewin-VHI [1994]). Because award rates are correlated with age (see Figure 8), an increasing elderly population suggests an increased burden in the future on SSDI.

In contrast to Social Security and pensions, replacement rates for new SSDI beneficiaries are generous; at the first quartile, replacement rates over the last decade have been approximately $55 \%$ for men; for women they have been close to $85 \%$. At the median, replacement rates are $46 \%$ for men and $61 \%$ for women. It is apparent that individuals should not rely on disability payments as their primary source of retirement income before age 65 . While the SS trust fund is projected to have surplus through 2015 and become exhausted in 2044, the Disability Insurance Trust Fund is expected to become insolvent in 1995 (CBO, 1993). In 1977, the denial rate on disability applications 
was increased due to financial pressures (Lewin-VHI [1994]). During subsequent years, evidence suggests that the increased denial rate was responsible for a decrease in applications (Parsons [1991b] and Lewin-VHI [1994]). This episode in history may provide useful insight into projections of future disability determination and receipt of award. Over the last decade, the prevalence of disability in the United States among working age persons has remained constant, as shown in Figure 9.

\section{A. Literature Review and Previous Methodology}

Common static models for investigating disability insurance include least squares and instrumental variables (because of correlation using self-reported health). There have been relatively few studies that have employed pure time series data to investigate the relationship between macroeconomic events and applications for DI (such as an increase in the unemployment rate). This is in part due to the implausibility of a stable relationship accurately describing application rates in light of institutional changes over the relevant time period. For example, Lewin-VHI [1994] cite Hambor [1992], who finds a negligible effect of a one percentage point increase in unemployment, once dummy variables for changes in the law are included. Other studies have used cross sectional data and variation across states to address the relation between unemployment and DI applications. Bound and Waidmann [1992] use pooled data to incorporate both time series and cross sectional features in their model.

There have also been a number of models that have attempted to capture the dynamic nature of the disability application decision using pooled individual-level data. Such data have been used often to characterize other decision processes such as the labor force participation decision and the Social Security application decision. Dynamic modelling of DI applications and awards is more complicated, due to uncertainty related to receipt of benefits and the cost (social stigma?) associated with applying. Haveman, DeJong, and Wolfe [1991] use a switching regression model to mimic the decision process of a worker choosing between working at the offered wage versus receiving disability. In their data set, about two-thirds of the sample receive disability benefits (SSDI); of these 
$90 \%$ do not work. They predict that a 20 percent increase in expected SSDI benefits would decrease the labor force participation rate by $0.3 \%$. Thus they conclude that the increase in benefits per recipient of $43 \%$ could not have been responsible for the $12 \%$ decrease in labor force participation of 55-64 year-old males between 1968 and 1978 .

Burkhauser, Butler, Kim, and Slotsve [1992] use a multi-state, continuous time hazard model and choice-based sampling to model the application for disability. They consider the decision process as one where the individual is choosing how long after the onset of a health condition to wait to apply for disability benefits. Some of the justification for waiting comes from the uncertainty of actual receipt of benefits. They modify a dynamic retirement model to estimate the optimal age at which an individual should apply for benefits, assuming perfect capital markets and uncertainty regarding program acceptance. The key assumption is that the individual will not return to work once deciding to apply, regardless of the outcome of the application.

Stern [1988] characterizes the endogeneity between the disability application and labor force participation decisions using a simultaneous equations framework. With a two-step estimation procedure, he finds that while disability (as measured by a number of physician diagnosed conditions or self-reported) affects the labor force partipation rate, participation does not seem to directly affect disability. Maximum likelihood estimates suggest some effect of participation on disability, but the sign of the coefficient on participation suggests that it diminishes health status. While the results imply that disability is a reasonable measure with which to predict labor force participation, there is no measure of disability benefits in the model (as noted by Stern). The methodology (of correcting for potential endogeneity) should be employed in related contexts, such as in comparing the relationship between labor force participation and the application for disability insurance.

Bound [1989] also cautions about potential endogeneity. In particular, the magnitude of the disincentive effect will vary across individuals and will be a function of past labor force behavior. Comparison of alternative decisions is difficult at the individual 
level because wages of those individuals out of the work force and disability benefits for those at work are not observed. To address this issue of endogeneity, Bound [1989] examines rejected disability applicants, claiming that this group forms a "control" comparison group. The key assumption that he makes is that individuals in this control group are healthier and more capable of work than those receiving disability benefits. In addition to finding (as noted above) that the majority of rejected applicants do not return to work, Bound notes that among those that do return, earnings are substantially lower than both pre-application levels and than non-applicant comparison groups.

In a response to Bound [1989]'s results, Parsons [1991a] re-emphasizes the endogeneity of the rejection on future labor force participation. In particular, he notes that following a denied application, individuals are likely to encounter difficulty returning to work after the 5-month waiting period, in addition to possibly opting to stay out of the labor force due to potential appeal or re-application. Parsons argues that even after application denial, the disability system plays a significant role in individuals' future labor force participation decisions.

In Rust [1989]'s model, a disabled individual is still allowed the full range of transition states; potentially this allows assessment of how receipt of SSDI inhibits or encourages re-entry into the labor force. Unlike models that incorporate Social Security, in modelling disability it is important to capture the uncertainty surrounding receipt of benefits conditional on application. Rust and Phelan [1993] are working on incorporating the DI application process into their dynamic specification. It will be important to think about the correlation structure between these decisions.

Before we propose policy aimed at effecting a particular response, it is important to establish whether there is a causal link (and what is the magnitude of any potential effect) between increased generosity of benefits and declining labor force participation. Unfortunately, there is still considerable disagreement in the literature about the relationship. Earlier work by Parsons [1980] attributed the decline of the labor force nonparticipation rate of older men since 1946 to the expansion of the disability program. In response to 
this work, Haveman and Wolfe [1984] criticized Parsons' results, citing potential endogeneity, multicollinearity, and sample selection problems with his estimation. Although they use a different dataset, they sequentially correct for each of these cited problems and conclude that doing so results in an insignificant elasticity of nonparticipation with respect to benefits. Parsons [1984] takes issue with their arguments; perhaps most convincing is a graph (see Figure 10) of the relationship between the nonparticipation rate of men 45-54 and the recipiency rate of Social Security disability benefits. While such graphical evidence does not designate causality, it does suggest existence of a correlation between the two rates. ${ }^{7}$

\section{B. What We Would Like to Know}

A fairly comprehensive discussion of the problems in econometric modelling of SSDI applications and awards is found in Lewin-VHI [1994]. Most studies have used crosssectional data for modelling disability. Among the problems with time series data, they cite the lagged response of DI applications to shifts in macroeconomic variables. Modelling the lag structure is nontrivial; however, analysis of impulse response functions or other spectral techniques could be useful in this regard. Lewin-VHI [1994] also cite low frequency of data; indeed the Hambor [1992] study contained only 22 observations. State space filtering algorithms would allow mixed frequency data to be used in modelling.

Lewin-VHI [1994] suggest separate analysis of time series data for subgroups of the population. However, it does not seem that data are currently available to enable such an analysis. The pooled data across states could be useful for this. Multivariate structural break models (see, for example, Bai, Lumsdaine, and Stock [1994]) allow endogenous determination of structural change and would therefore control for key institutional changes as discussed above. By precisely estimating the date of change, inference can be drawn about the lag structure and the propogation mechanism of shocks.

\footnotetext{
7 In fact, the correlation in Parsons' data from 1947-1979 is 0.91 .
} 
As with the decision to accept a pension-covered job, selection occurs among disability applicants as individuals assess their probability of acceptance. In order to control and correct for selection, a data priority should be to collect more accurate applicant surveys. Some use of subjective probability questions may prove valuable in this regard to evaluate how an applicant (as well as a non-applicant) assesses the probability of an award. Detailed data recommendations are contained in Lewin-VHI [1994]. They identify the need for a pooled data source. In addition, they suspect that concurrent applications (for both SSDI and Supplemental Security Income - SSI) are highly sensitive to changes in the labor market or the macroeconomy. A pooled data source may provide a means of distinguishing such trend components in disability.

Understanding the link between disability and retirement is the first step to being able to predict how changes in Social Security policy will affect disability applications. To the extent that they are complements, an increase in the Social Security retirement age may induce more individuals to apply for disability. To verify this, we must first ascertain the direction of causality - are people applying because they are ready to leave the labor force or does the very act of applying cause individuals to drop out of labor force (due to stigma or the long waiting period or other reasons)?

An additional uninvestigated research topic is the interaction between window plans and SSDI. Lewin-VHI [1994] suggest that windows are more likely to be attractive to those that are eligible for SSDI. This contradicts other evidence on window plans that suggests that the "wrong" individuals (i.e., those with attractive alternative employment opportunities) leave. Particularly with regard to disability insurance, where there is uncertainty about acceptance of the application (as opposed to Social Security, pensions, and Medicare, where acceptance depends solely on quantifiable characteristics such as age and years of service), selection issues are likely to play a key role in inference. Parsons [1991b] models self-screening in SSDI - the extent to which individuals pre-assess their probability of acceptance and condition their decision to apply on this preliminary analysis. Parsons investigates self-screening efficiency, that is, the accuracy of this selection mechanism. 


\section{Medicare and Health Insurance}

Much of the concern regarding the adequacy of retirement income is due to the uncertainty surrounding future events and needs, particularly health status and health care costs. Elderly individuals over age 65 are covered by Medicare and/or Medicaid, so that very few are uninsured. In 1990, 99 percent of those $65+$ were insured (CBO, 1993) while $10 \%$ of men and $13 \%$ of women between ages $55-64$ did not have insurance. In 1987, $94 \%$ of people $65+$ incurred medical expenses (not including long term care). Individuals $65+$, as well as those that have been receiving disability for over 2 years, regardless of age, are eligible for Medicare. Among those 55-64 in 1987, 85\% incurred some medical expense (not including long term care). Of those that were retired in 1987, $70 \%$ held employment-related coverage. Post-retirement coverage is more prevalent in large firms; in $1990,90 \%$ of the largest firms provided post-retirement coverage (Hewitt Associates [1990]), $83 \%$ for individuals both before and after age 65 . Of these, approximately $20 \%$ required no contributions, an additional $8 \%$ required contributions for spouse coverage only. For post- 65 coverage, $31 \%$ did not require any employee contributions. Most post65 retirement plans $(97 \%)$ are integrated in some way with Medicare. However, even with Medicare coverage, individuals are facing increased out-of-pocket expenses. The percentage of Medicare enrollees' per capita income needed to cover such costs increased from $4.2 \%$ in 1975 to approximately $5.7 \%$ in 1990 (Kingson [1992]). Rising medical costs and costs of insurance may result in a decrease of pension benefits or a decline in retiree health benefits (Congressional Budget Office [1993]). In the 1960s, Medicare disbursements were estimated to be approximately $0.6 \%$ of GNP; in 1991 their share of GNP had doubled to $1.2 \%$ (Hurd [1994b]); this share is projected to be $2.7 \%$ by 2020 (also Hurd [1994b]).

Like Social Security and Disability Insurance, Medicare is not adequately financed in order to meet the anticipated increase in health care needs. Under moderate projections, Medicare funds are expected to be depleted by 2003. In order to sustain the program, therefore, a combination of tax increases, benefit reductions, and cost containment will be necessary (Kingson [1992]). As a result, retiree health insurance is increasing in 
importance. Like other fringe benefits such as pensions, retiree health insurance may have powerful incentive effects. In particular, the existence of retiree health insurance should reduce job mobility to the extent that it represents an implicit contract between employer and employee. An implication of this, Macpherson [1992] argues, is that women should be covered less frequently than men, due to less attachment to the labor force. In addition, large firms, which presumably have high monitoring and training costs, are more likely to offer retiree health insurance (creating a "bonding" effect, similar to that for pensions, as argued by Allen, Clark, and McDermed [1993] and Gustman and Steinmeier [1993b]). Per capita costs of retiree health insurance will also be lower at larger firms. Barron and Fraedrich [1994] take a similar view, focusing on employer heterogeneity to explain differences in fringe benefit offerings, particularly with respect to retiree health insurance and leave policies.

Another reason it is important to include Medicare in a model of retirement behavior is that an individual is eligible for Medicare due to disability if $\mathrm{s} /$ he is entitled to Social Security on the basis of a disability; that is, they have been receiving Social Security for this reason for at least 2 years, under age 65. It is estimated that approximately eighty percent of SSDI beneficiaries receive Medicare coverage (Lewin-VHI [1994]). If the individual goes off disability and goes back on again for the same disability, the 2 year waiting period is waived. In addition, there is a continuation allowance if the individual returns to work (a 9-month trial period and up to 15 months afterwards, Commerce Clearing House, Inc. [1993]). As with non-disability-related cases, if the individual is covered by an employer-sponsored plan, Medicare is the secondary payer.

Besides Medicare, government influence in health benefits to the elderly has occurred via legislation, such as passage of the Consolidated Omnibus Budget Reconciliation Act of 1985 (COBRA), which mandated continued health care benefits to retired employees for up to 18 months. While provisions of COBRA allow employers to charge up to $102 \%$ of premium costs, many plans pay the entire cost of this continuation coverage (Barron and Fraedrich [1994]). For individuals that remain attached to the labor force solely 
due to the availability of health insurance until eligibility for Medicare at age 65, this effectively lowers the feasible retirement age to $63 \frac{1}{2}$.

\section{A. Literature Review and Previous Methodology}

As noted earlier, papers by Lumsdaine, Stock, and Wise have systematically underpredicted retirement rates at age 65, despite reasonable predictions at other ages. LSW [1993] addresses this issue directly, focusing on two selected samples from a specific firm: a balanced sample of individuals (the same number from each age group; random samples tended to have relatively few individuals at the older ages) and a sample of 65 year olds. Standard economic variables do not seem to explain the large retirement rates at this age. Discussion by Rust [1989] and Rust and Phelan [1993] suggests that this underprediction may be due to the absence of health benefits in the model specification. The specific firm that LSW [1993] study offers continued post-retirement medical coverage, leading the authors to argue that the incentive to stay employed to retain health insurance should not apply to individuals in this firm. Nonetheless, the spike in the hazard rates at age 65 is still noticeably pronounced. In addition, Madrian [1993] has computed hazard rates using three aggregate datasets for individuals with and without retiree health insurance; the difference is not statistically significant between the two groups and in one case, the hazard rate is actually lower for those with retiree health insurance than for those without it.

Gustman and Steinmeier [1993a] note that, "[r]etiree health benefits create incentive effects that are analogous to those created by defined benefit pension plans." In particular, it is advantageous to remain with the firm until the age of eligibility for such benefits. In considering the interaction between employer provided health insurance and retirement behavior, they predict a minor effect on labor supply; the magnitude of the effect is considerably less than a year. Gustman and Steinmeier simulate the effects of a variety of retiree health insurance assumptions. Because no dataset contains all the important information for such a simulation, they estimate a life-cycle model using the RHS and embed the resultant estimated utility function into a simulation model using 
data from the SCF. In doing this, they are able to both model the key elements of the retirement decision and incorporate detailed features of pension plan provisions. The measure of health insurance used in their simulation is an imputed amount of employer contribution. Post-retirement health insurance is a fraction of the value of this contribution, based on national averages. As with their [1991] study on the impact of policy changes to Social Security, Gustman and Steinmeier measure the effect of providing retiree health insurance to be a change (in this case a decrease) in the average date of retirement of roughly the same magnitude; individuals would retire approximately three weeks earlier. They attribute this modest effect to the magnitude of the value of health insurance relative to other forms of compensation.

Lumsdaine, Stock, and Wise [1994a] incorporate Medicare into the base retirement model, valuing medical insurance at its cost and treating it as comparable to wage compensation. The addition of this measure of the value of medical insurance does nothing to explain the departure rate at 65 . In principle, other things such as savings also could be incorporated in this way.

It is puzzling that some structural models such as those of Lumsdaine, Stock, and Wise [1994a] or Gustman and Steinmeier [1993a] fail to capture a significant Medicare/health insurance effect, as anecdotal evidence and media attention suggest that concern over health insurance is on the minds of many individuals nearing retirement. Reduced form models have been more successful at capturing a larger effect, at the expense of policy inference. Using a probit model, Gruber and Madrian [1993a] find a significant effect of post-retirement health insurance on retirement, exploiting state cross sectional variation in continuation of coverage laws. They find that one year of continuation benefits raises retirement rates by $20 \%$. In addition, the effect is not clustered near the age of Medicare eligibility but rather is similar at all ages. Their results suggest that individuals value continuation benefits at a much higher level than at actual employer cost. Subsequent work by Gruber and Madrian [1993b] finds that continuation mandates have a large effect on increasing insurance coverage, but have a relatively small effect on increasing retirement. Karoly and Rogowski [1993] also use a probit model and find sig- 
nificant effects of health insurance on retirement. Because they use the Survey of Income and Program Participation (SIPP), which has no information on retiree health benefits, they use an imputed measure of benefits, based on firm size, industry, and region.

Rust and Phelan [1993] use dynamic programming as in Rust [1989] to model jointly the labor supply decision and the decision to apply for Social Security using the RHS dataset. They cite the liberalization of Social Security and Medicare benefits as a signifcant contributing factor in the decline of labor force participation. They also review some of the earlier techniques used to study this question. Regarding the impact of health insurance, they criticize earlier studies' (in particular Gustman and Steinmeier [1993] and LSW [1994a]) use of the expected value of Medicare reimbursements and employer contributions, arguing that risk averse individuals respond asymmetrically to the probability of a catastrophic event. Thus, "the certainty equivalent value of Medicare coverage will be substantially greater than the expected value of Medicare reimbursements and retiree health insurance premiums." They found that the Pareto distribution provides a very close fit to the long, thin upper tail of the distribution of annual health care expenditures. The large influence that Social Security exerts over labor force participation at age 65 is attributed to incomplete annuities markets. Additional responsibility for the large peak in retirements at this age is due to incomplete health insurance markets. In the dynamic programming model they use, Social Security is basically the only annuity available to the individual. In particular, the data are limited to men who do not have access to a pension plan. An obvious desirable extension to their model would be to relax this constraint. The model also assumes no savings (total borrowing constraints). The results justify retirements at age 62 and 65 (and mirror the peaks extremely well), with those at 65 being attributed to Social Security and those at 62 attributed to the presence of retiree health insurance or some other form of health insurance. Without health insurance, individuals typically postpone their retirement until they are also eligible for Medicare. The delayed retirement credit is blamed for the magnitude of the sharp peak at 65 (virtually no one will work after 65); this suggests a reduction in the peak in the future due to scheduled increases in the delayed retirement credit. Rust 
and Phelan predict that high income workers will continue to work but will still apply for Social Security at 65 as a costless way of obtaining supplementary health insurance, despite the limitation imposed by the earnings test.

\section{B. What We Would Like to Know}

One of the hottest topics of debate in the 1992 election, and likely to continue to be a key issue, is universal health care coverage. Opponents cite unsurmountable costs while proponents argue that lack of universal coverage reduces labor mobility and stifles entrepreneurship (by discouraging self-employment) because employer-provided health insurance, like DB pensions, are typically not portable and often contain preexisting condition clauses. Holtz-Eakin, Penrod, and Rosen [1994] investigate this latter claim. They find little evidence to support the idea that universal coverage will increase entrepreneurship, noting instead that the significant negative impact of the presence of an employer provided health insurance plan on the probability of a transition into self-employment is due to heterogeneity based on other observable characteristics.

While selection issues are likely to be important in analyzing the effects of retiree health insurance, they are less important in Medicare analysis since (as noted above) virtually everyone over age 65 is covered by Medicare. Barron and Fraedrich [1994] assume that employers offer fringe benefits to induce self-selection; this assumption arises in a model of labor contracting where certain types of firms need to reduce mobility of their employees, perhaps due to costly training which represents a long-term investment.

Another important point that Holtz-Eakin, Penrod, and Rosen [1994] raise is that of determining a reliable measure of expected health costs. They define 12 different proxies, including previous medical expenses associated with hospital stays, the number of doctor visits, and the number of people in the family covered by the plan, incorporating each one separately. It is likely that a weighted combination of many proxies would be the most accurate in determining the influence of retiree health insurance. 
Because Medicare provides near-universal coverage for elderly over age 65, policy related to it is likely to focus on issues of cost containment. Two approaches that have been discussed are capping expenditures/rationing of services and raising the Medicare eligibility age. To the extent that some of the observed retirement at age 65 is due to Social Security and some is due to Medicare eligibility, attempts to increase labor force participation by raising the Social Security normal retirement age, increasing the Social Security early retirement penalty, and increasing the DRC will be offset. As life expectancies increase and the population ages, the Medicare trust fund in its current state will be expected to support greater numbers of elderly.

It is equally critical, in light of the above-mentioned policy experiments, to be able to assess the direction of causality between Medicare and retirement. Although the 1983 Social Security ammendments raise the normal retirement age and application of the DRC from 65 to 67 (as noted in Section III), a commensurate increase in the age of Medicare receipt has not been legislated. It is therefore possible (for example, the RustPhelan [1993] model suggests) that the intended impact of these ammendments will be dampened if individuals are health insurance constrained and the retirement peak may well remain at 65 . To the extent that Medicare influences the retirement decision, increasing the Medicare eligibility age may be another avenue by which policymakers can increase labor force participation. If, instead, Medicare application occurs because other sources of health insurance are limited at age 65 , increasing the eligibility age may have the undesirable effect of raising the proportion of uninsured individuals.

Besides documenting the relationship between Medicare and health insurance on labor force participation and retirement, future research should focus on the policy implications of such relationships. Holtz-Eakin, Penrod, and Rosen [1994], for example, find that for a subsample of individuals who were continuously employed, the number of doctor visits over the last four months is a significant predictor of a transition to self-employment. They note, however, that the quantitative relevance of this significance is limited, predicting an increase in the transition probability of $.35 \%$ for this part of the population. This is consistent with findings of Gustman and Steinmeier [1993a] 
and Lumsdaine, Stock, and Wise [1993] that despite significant coefficients on employerprovided health insurance in their structural retirement models, the quantitative effects of a change in coverage would be small in magnitude.

Most of the dynamic models used in examining retirement behavior arise from a life-cycle framework. Just as current labor force participation decisions depend on the individual's entire work history, attitudes toward the importance of health insurance and the valuation of health benefits can be inferred in a life-cycle manner. These attitudes are likely to differ substantially across individuals and depend on observable characteristics such as those mentioned in Holtz-Eakin, Penrod, and Rosen [1994]. Lumsdaine, Stock, and Wise [1994a,b] include expected premium as a proxy for medical expenditures in a base specification [1994a] and in simulations [1994b]. They find little effect of medical benefits on retirement. As noted by Rust and Phelan [1993], this limited allowance for heterogeneity may not adequately capture the manner in which individuals assess such benefits. While it is clear that individual-specific effects (such as highly correlated error terms which capture unobserved persistent heterogeneity such as individual health status) are important to dynamic models, it is also important in this context to model uncertainty, as there is substantial evidence that individuals are highly risk averse and their demand is driven not by considering a certainty equivalent but in adequately insuring against the probability of a catastrophic event.

One of the ways in which dynamic specifications could be improved is by including an estimate of the individual's expected present discounted value of medical expenses, using either combined premiums and out-of-pocket expenditures or total expenditures including insurance payments. These could be imputed in a manner similar to predictions of future wages, based on observable demographic characteristics and a dataset (such as the National Medical Expenditure Survey) which contains detailed information on health care expenditures. Another way to allow for more heterogeneity in models is to incorporate individual-specific life expectancies (also imputed from observable characteristics). Such imputations still would enable use of datasets with details on pensions and earnings. 
Ideally individual heterogeneity can be included by incorporating self-assessed health status. A limitation of the firm-specific datasets of Lumsdaine, Stock, and Wise, for example, is that information on health status is missing. The HRS combines detailed questions on health with specific pension plan information and will allow researchers to model a richer set of dynamics than was previously possible.

\section{Hours Flexibility and Career Jobs}

In their models of retirement behavior, Gordon and Blinder [1980] and Reimers and Honig [1993] assume that workers can work any number of hours they choose at a constant hourly wage. However, there is much evidence that workers are constrained in their choice of hours. Hurd and McGarry [1993a], using the HRS, find that 24.1 percent of respondents can decrease their hours; another 13.6 percent want to but cannot. In terms of increasing hours, 36 percent of respondents report being able to, with an additional 15.1 percent wanting to but unable. Over half of all respondents have no flexibility with respect to hours. Those who cannot decrease their hours but want to have a significantly greater probability of retiring at age 62 and 65 . Those who cannot increase their hours but want to have a greater probability of working full-time at age 62 and age 65 . Hill, Soldo, and $\mathrm{Li}$ [1993] find that having access to flexible work hours is positively correlated with work hours.

There is evidence that hours flexibility will become an increasingly important job characteristic. "With the growing complexity of family structure and resulting caregiving demands, flexible work strategies will be required to keep both young and old workers in the labor force" (Kingson [1992]). Modelling hours flexibility is especially important when studying the labor supply behavior of women. Currently $74 \%$ of women aged 25 54 are in the labor force; this is expected to rise to $82 \%$ by 2005 (Kingson [1992]). In addition, "about $40 \%$ of full-time private sector wage and salary workers are women," (Korcyzk [1992]). Pienta, Burr, and Mutchler [1993] suggest that a woman's employment status in later life is determined by the work history pattern over the course of her lifetime, concluding that "labor force behavior in later life is often a continuation of 
earlier adult decisions and behavior." In terms of concerns over income inadequacy a reduction in income will translate into less Social Security and pension income, placing women potentially at even greater risk. Korcyzk [1992] concurs, noting that gender differences in pension coverage arise from different employment patterns (recall Table 3). Blank [1994] also provides evidence of such gender differences. Looking at working age women, she finds that $40.5 \%$ of women in her sample had been in all three states of labor force participation (full-time, part-time, out of labor force) during a 14 year period, as opposed to just $6.3 \%$ of men.

One reason to investigate more flexible hours in the workplace is increasing evidence that individuals would prefer to gradually reduce their amount of hours worked, as opposed to an abrupt transition from full-time to completely retired. Reimers and Honig [1993] and Hurd [1993a] argue that insitutional rigidities impede an individual's ability to do this. Because of this, retirement has often been modeled as a dichotomous decision as opposed to a continuous choice (of how many hours to supply). In particular, Reimers and Honig [1993] state that, "Institutional rigidities make it unlikely, however, that people can reduce hours of work on career jobs."

\section{A. Literature Review and Previous Methodology}

Hurd [1993] summarizes some of the institutional rigidities that impede complete flexibility in hours determination. Some of these are due to fixed employment costs and requirements of team production. Impediments to job change arise from loss of job-specific skills, creating an unwillingness of employers to invest in training for an older worker. Other rigidities are due to regulation and policy towards factors affecting retirement; some of these, such as the Social Security earnings test, DB pension plans, and health insurance, have already been discussed.

As evidence of a gradual transition toward retirement, Quinn and Burkhauser (1992) find that "the importance of part-time work rises dramatically with age". Using data from the US Bureau of Labor Statistics, they note that 16\% of men aged 60-64 work part-time (less than 35 hours/week), while a full $50 \%$ of men over 65 do. For women, 
these percentages are $33 \%$ and $60 \%$, respectively. The proportion of individuals working part-time has grown steadily over time. Therefore, Quinn and Burkhauser conclude, individuals are still exhibiting a tendency towards early retirement, but through a reduction in hours. Of those who switch employers, Quinn, Burkhauser, and Myers [1990] find that $75 \%$ were still on the job after a year, almost $60 \%$ after two years. Departures from career jobs tended to be characterized by a decrease in wage, with many transitions associated with a complete change of industry and/or occupation (Ruhm [1990], Parnes and Sommers [1994]). Gustman and Steinmeier [1986] incorporate wage reduction into a model of leaving full time work.

Ruhm [1990] also finds substantial evidence for a gradual transition, noting that, in the RHS, "only $36 \%$ of household heads retire immediately on the end of their career positions, and nearly half remain in the labor force for at least 5 additional years." This is even more pronounced at the younger ages; of those aged 55-59, only $11.6 \%$ retire completely. In addition, there are often financial reasons why an individual might want to exit a career job, thus becoming eligible to receive a pension benefit, and then may want to continue to work (the opportunity to earn additional wages, combined with health coverage until eligible for Medicare at age 65). These incentives usually decline upon receipt of Social Security, however, due to the earnings test. Ruhm [1990] finds that $47.7 \%$ of workers eligible for a pension continue to work after leaving their career job. The observation that partial retirement occurs mainly between ages 62 and 67 indicates the influence of the Social Security earnings test. In terms of reentry, nearly $25 \%$ of retirees reenter the labor force, with almost one-third choosing full labor force participation.

While some people define retirement as "receiving retirement income" or "no longer working", a gradual transition suggests a phase-in toward the retirement state that begins when one leaves their "career job". But even the definition of career job is ambiguous Reimers and Honig [1993] use "a job an individual had held since before age 55, provided he does not describe himself as either partially or fully retired." Ruhm [1990] uses "the longest spell of employment with a single firm, up to and including the position held 
at the beginning of" the RHS. Defining career job as a job which has lasted for 10 or more years, Ruhm [1994] shows that many elderly (individuals above age 58) who work full-time are not in a career job.

Over the past few decades, an increasing proportion of individuals claim to have retired voluntarily (that is, because they wanted to, not, as in the past, due to health constraints or being laid off). Some of this may be attributable to the earlier ages of retirement (before health problems emerge), as well as to publicity presenting retirement in a positive light. Others may argue that the generosity of retirement benefits has made retirement more feasible; Hardy [1991] suggests that it is still important to distinguish between workers who choose retirement due to a perceived lack of alternative employment opportunites versus those who anxiously await a time of leisure. Parnes and Sommers [1994], using the National Longitudinal Survey of Mature Men (NLS-MM 1990), report that health problems were a considerably less important reason offered by nonworkers as to why they had no interest in working than a general preference for leisure. Less than $40 \%$ cited health reasons as a cause.

Some research has used discrete choice models to capture the retirement decision. The simplest of these is a binomial probit or logit; these models treat retirement as an all or nothing decision. It is clear, however, that employment (correspondingly, retirement) can no longer be modelled as a dichotomous variable. Individuals often face a wider range of choices along the labor/leisure frontier. Other research has used a multimomial logit model (e.g., Hardy [1991], with retiree, reentrant, available worker, or Anderson, Burkhauser, and Quinn [1986], with early, on time, late retirement). Additionally, one could consider an ordered choice model (make retirement choice, then decide what to do - nothing, work parttime or take a new full-time job). Which model is most appropriate is linked to perceptions of behavior and dynamic decision making.

Reimers and Honig [1993] use the RHS and consider re-entry into the labor force after leaving a "career job" using a hazard model. They find that the Social Security earnings test affects re-entry; a ten percent increase in the level of exempt earnings is 
associated with a $5 \%$ increased probability of re-entry. Hayward, Hardy, and Chiang [1990] use the NLS-MM in a similar fashion. They note that the risk of reentry declines precipitously after two years out of the labor force. In addition, more than twice as many reentrants move back to full time and wage and salaried jobs versus part-time and selfemployment, respectively. Unfortunately, neither of these datasets contains substantial detail on pension coverage or receipt, so it is impossible to determine the extent to which re-entry is a means of supplementing a pension benefit or obtaining health insurance. They do find, however, that the number of previous retirements is negatively correlated with re-entry into a full-time job; this is attributed to barriers that exist for those who exhibit labor force mobility late in life. Scott, Berger, and Garen [1992] suggest firms that offer generous (DB) pension or health benefits are less likely to hire elderly (55-64) workers. In contrast, the hiring practices of firms offering DC plans appears to be age neutral. In terms of encouraging more elderly labor force reentry, Hayward, Hardy, and Chiang [1990] conclude that, "the results imply that there is little that job training policy can do to influence reentry into wage or salaried positions or jobs that are full-time. Skill deficits do not appear to be the key problem." Reimers and Honig [1993] concur, citing the "apparent paucity of part-time jobs".

Reimers and Honig [1992] consider gender differences in re-entry behavior by modelling a re-entry hazard function. They conclude that men behave "myopically" with regard to Social Security, considering only their current level of benefits, while women are "far-sighted", responding more to varying levels of Social Security wealth. They argue that older women's labor force participation is not affected by the earnings limit, as older women are likely to be in lower wage jobs. In addition, the amount of private pension influences the re-entry decision of men, but not women. Such gender differences suggest differential impact of proposed policy changes.

Blank [1994] compares three dynamic discrete choice models of labor force behavior: a 3-lag model which allows for complex dependence of the current decision on a short history of past labor force participation decisions, a 13-lag model which has a simplified dependence structure but allows influence of a longer history, and a random effects logit 
model, which ignores previous history but allows for unmeasured heterogeneity. All three models perform fairly well in predicting aggregate behavior. In terms of individual behavior, however, the two models that account for previous decisions are substantially better (more than ten times so) at predicting actual behavior.

Daula and Moffitt [1989] and Berkovec and Stern [1991] estimate dynamic programming models of job transition. Daula and Moffitt considered military retirement, where at each period an individual decides whether to stay or whether to leave the service; Berkovec and Stern allowed for four transition states from full-time work - continuation, switch to a new full-time job, partially retire, fully retire. Both models specify a value function, which depends on age, years of service, and other exogenous variables. There are individual-specific error terms; Berkovec and Stern take these to be "random components of the wage which are independent across time, matches, and individuals" and assume that they have an extreme value distribution in order to obtain analytic solutions via the method of simulated moments. Daula and Moffitt also allow for heterogeneity, assuming that their errors are "uncorrelated over time and normally distributed".

Ausink [1991] considers retirement from the military of a sample of Air Force pilots. Although the military pension has cliff vesting at 20 years of service, many individuals leave, either voluntarily or involuntarily, before this time; even among those that stay, eligibility for military pension typically occurs when individuals are in their 40s. Thus the choice for most military individuals is not one of retirement but of exitting a career job. Two items of particular importance for a model of such behavior are the determination of the following:

a ) The Date of Exit. Since the individual is expected to enter a new full time job, it is important to evaluate the expected wage trajectory. For example, as noted by Ausink, civilian pilots typically have greater earnings potential than military pilots although starting salaries are lower. However, most airlines compensate based on years of experience at their specific firm and do not reward based on total years of tlying experience. A dynamic decision process therefore involves determining the optimal time 
of retirement, evaluating the tradeoff between pension receipt, compensation, and the present discounted value of future compensation in an alternative employment setting.

b ) The Form of the Pension Benefit. Many plans offer a wide array of distribution choices upon electing to receive a pension benefit, from a lump sum to a fixed term to an annuity payment. Often the present discounted values of various options differ substantially. In addition, there is evidence that often such distributions (especially in cases where individuals continue to work) are not applied to retirement saving but are instead used for other purposes. Of particular note is an individual that takes a lump sum distribution from a pension at a career job and uses it to start a business and be self-employed later in life.

Ausink and Wise [1993] consider the effects of changes to the Air Force pension plan, reflecting some of the actual changes that have been implemented in the last decade. In addition, they compare the Stock-Wise "option value" model to the Air Force's "Annualized Cost of Leaving (ACOL)" models as well as to dynamic programming specifications similar to those of Lumsdaine, Stock, and Wise [1992].

Rust [1989] proposes incorporating partial retirement and multiple labor force transitions into a dynamic retirement model. The difficulty in capturing multiple labor force decisions in behavioral models used for prediction is a numerical one; every combination of transitions must be considered. In addition, the decision tree involves an exponential number of nodes; if the alternatives are working or not working (retired) over $n$ future periods, $2^{n}$ transitions are involved. Adding the possibility of part-time work increases the number of transitions to $3^{n}$. The computational burden associated with such a model is formidable.

According to the CBO [1993], "As long-term employment for a single firm is becoming less common, the risks of defined benefit plans are rising." This is due to the lack of portability in defined benefit pension plans. The link between pensions and the career job, as well as implications for retirement and retirement income, has been documented in the literature. Mehdizadeh and Luzadis [1994] simulate the effects of a number of 
different combinations of job mobility and type of pension plan to analyze the potential impact of such choices on retirement income. In particular, they find that pension plans that are integrated with Social Security tend to hurt the financial well-being of their recipients relative to an equally generous plan without such a provision. These simulations are illustrative, but far from comprehensive. It would be interesting to simulate a retirement from career job followed by a series of shorter jobs, all with pension plans. In particular, it is possible, because of shorter vesting periods and the incentive effects in defined benefit plans to retire early, that such a strategy may increase retirement income. As pensions become an increasing source of retirement income, attention will focus on the adequacy of retirement income from the primary employer (Mitchell [1992], Hurd [1993], Ruhm [1990], Perrachi and Welch [1994]). However, it is argued that pension incentives encourage retirement from one's primary job. If perceptions regarding retirement income are inaccurate, retirees will be forced to return to work.

\section{B. What We Would Like to Know}

As institutional barriers to flexible hours break down, we will need to know how to model the continuous transition into retirement. Reimers and Honig [1992] attribute exit and re-entry behavior to worker response in an environment where hours cannot be smoothly adjusted to accommodate an increasing preference for leisure. In addition, Pavalko, Elder, and Clipp [1993] note a link between work history and mortality. They recommend improvements in modelling worklives and incorporating entire work histories. One possible reason they offer for increased mortality risk associated with multiple transitions between unrelated jobs is due to inadequate pension and health insurance benefits, which may cause increased stress surrounding retirement.

Because of the evidence that labor force decisions, particularly those of women, depend both on economic and non-economic considerations, Pozzebon and Mitchell [1989] argue that women's retirement behavior ideally should be modelled in a life-cycle framework. As a simplification, they model the wife's decision conditional on the husband's decision, using the RHS. As they note, a joint decision model would be more general. 
In order to project future income streams, they designate a planning date. Others (e.g., LSW) have imputed income streams at each future decision date.

A potentially fruitful way to model transitions in and out of the labor force is via the duration method used in Klerman [1992]. In a different context (considering spells with and without health insurance using SIPP data), Klerman considered each combination of runs. For example, over 7 periods, the number of combinations would be $2^{7}$. He then related these runs to a variety of explanatory variables. To the extent that individuals' labor supply behavior is determined over the life-cycle, such a model provides a useful framework for examining the dynamic decision process. The computational burden, being exponential, quickly becomes formidable due to loss of degrees of freedom. This method would be computationally cumbersome for investigating employment decisions over the course of one's adult life. It is well suited for considering exit and re-entry patterns of the elderly, particularly after exitting a career job.

As noted above, many individuals return to work after retirement from a career job. This must be modelled explicitly; Rust [1994] suggests failure to do so attaches undue uncertainty to the retirement decision. It is also important to consider how labor force transitions, particularly re-entry, are correlated with other factors influencing the retirement decision, particularly pension benefit receipt. While much of the literature has focussed on a job transition resulting in a decline in pension wealth, for some individuals, such as those in Ausink's [1991] military dataset, it is expected that individuals will collect pension benefits from multiple sources (double- or triple-dipping).

Besides hours flexibility, other job characteristics will similarly affect transition decisions. Hurd and McGarry [1993a] consider a number of these, such as physical strain and attitudes of coworkers. Individual perceptions and self-selection are likely to play a key role in understanding labor force transitions and the effects of job characteristics, both for individuals on the verge of retirement and throughout their work histories. For example, in deciding whether to leave a career job, a worker may evaluate his/her probability of losing the current job or finding another job. Questions in the HRS are intended to 
capture these subjective assessments which may or may not reflect actual probabilities. Even without misperceptions, subjective probability assessments may allow researchers to capture otherwise unobserved heterogeneities. Identifying misperceptions will improve the way in which an econometrician can model the decision process, particularly when many existing models do not incorporate such uncertainties.

\section{Conclusions}

What determines retirement and retirement income? Often the definition depends on the research question being addressed. It is also clear, however, that over time our definitions have changed fundamentally, as, for example, labor force exit is associated more with a voluntary decision rather than stemming from necessity. It is possible too that some definitions are becoming less pronounced, such as that of a career job. In this section I summarize the key ingredients to a richer model of retirement behavior and income.

\section{A. Expectations}

Why are retirement rates so high at age 65 ? The work by Lumsdaine, Stock, and Wise consistently underpredicts retirement at this age, despite being able to accurately capture retirement behavior at other ages. They attribute much of the peak to "social custom"; either via influence form coworkers or general social norms. How these norms are formulated is not addressed, but could be due to indirect influences of Social Security and Medicare, which cause certain ages to be associated with retirement. That modal retirement ages may be determined via social custom is echoed in Leonesio [1993a,b]. In addition, he cautions that policy analysis must consider endogenously determined expectations, and how a proposed policy may affect future expectations. He thus speculates that policies to encourage later retirement may generate the desired response and that, as expectations and perceptions about working longer become more positive, the observed effect will be greater than initially estimated. 
Responses to questions in the HRS about why individuals retired, and how much they knew, planned, or discussed with others before retirement will shed light on whether or not there has been (as put forth by a number of authors) a trend towards more voluntary retirements and whether individuals properly assess factors influencing their retirement decision. We do not yet have aggregate evidence on the extent of misperception, but based on evidence in Bernheim [1994], using a sample of baby boom individuals, households save well below their self-perceived target level. According to the GAO [1990], of 25 million workers who were in defined benefit pension plans, 18 million (72\%) were incorrect regarding or did not know when they could retire with full benefits ( $16 \%$ said they did not know). 22 million ( $88 \%$ ) of these individuals were in plans with an early retirement option. Of these, almost $14 \%$ did not know whether or not they were eligible for such an option; an additional $27 \%$ were incorrect in assessing their eligibility. Leonesio [1993a] discusses misperception regarding Social Security provisions, saying "This raises a number of interesting questions about the accuracy of predicting the behavioral consequences of changing a provision that is poorly understood."

Evidence from a military "window plan" suggests inadequate understanding/perception of the variety of distributional options offered; in the particular case examined, the lumpsum choice of distribution is far from actuarially fair (amounting to between 40 and 55 percent of the annuity when compared in present discounted value terms, using a discount rate of .95), yet this form was preferred almost 10-1 over the annuity among the enlisted populations, with an almost even split among officers. According to a sample of individuals who opted for the program, the reason given for taking the lump-sum option was "primarily to pay off debts of to have a cash reserve while seeking employment", while majors reported choosing the annuity because of the "perceived greater overall value and the guarantee of long-term income." 8

In addition to improved public understanding regarding things like Social Security and private pension plans, which are aimed directly at the timing of retirement, there

${ }^{8}$ I am grateful to John Ausink for providing the numbers and information in this paragraph. 
are many indirect influences as well. These include policies designed to increase savings (such as the introdution of IRAs, 401(k)s and their tax-advantaged status, see, for example, Venti and Wise [1992]) and publicity about the benefits of working after exiting a career job (Day [1993], Bernheim [1994], Employee Benefit Plan Review [June 1994]). In general, there is evidence that the public responds to such campaigns; Venti and Wise [1992] note that, "several aspects of the public response to IRAs in the 1982 to 1986 period suggest to us that the fanfare accompanying IRAs was an important ingredient of their success."

What are expectations about future window plans? Anderson, Burkhauser, and Quinn [1986] considered male workers in the RHS and found that "...(about 60 percent) left work within a year of their predicted date." Instead of focusing on the determinants of the retirement decision, they were interested in the relation of actual retirement to expected. Of those that did not retire on their predicted date, more retired earlier than expected. In contrast, Bernheim [1989], using the same dataset, finds little relationship between the expected date of retirement and the mean date (the average over all individuals that report the same expected date). However, he finds evidence that individuals respond to the question of when they expect to retire with the modal value (he terms this "The Modal Value Hypothesis"). In fact, the modal date of retirement corresponds with the expected date in $75 \%$ of the groups. What kind of options do elderly workers face and is this choice set narrowing with age? Answers to these questions may or may not match perceptions about the probability of a new job.

How do we model expectations? What is the accuracy with which we can model them or with which individuals can evaluate their own expectations? These questions are difficult to answer because, as noted earlier, the dimensionality of individual beliefs is very large. Bernheim and Levin [1989] analyze expected Social Security benefits and their effect on individual savings levels. Hurd and McGarry [1993b] provide evidence that individual assessments regarding probability are remarkably close to population averages. In addition, these assessments vary along demographic lines, in ways analogous to actual probabilities. This provides optimism for using such survey responses 
for prediction and forecasting, although current expectations reflect the current state of the world and will not necessarily agree with future probabilities. Because they at most incorporate all current and past information, they obviously are unable to capture significant legislative or health changes in the future. Adequately modelling expectations and uncertainty surrounding these latter changes, which perhaps represent the biggest threat to retirement income security, is crucial to understanding the factors influencing labor force participation decisions and represents a substantial challenge for future research.

\section{B. Endogeneity}

This paper has documented a number of forms of endogeneity in assessing retirement behavior and income. The first form emphasizes the need for models that specify a dynamic system of equations which incorporate the interactions between decisions regarding retirement, from leaving a career job to applying for social benefits such as Social Security, Medicare, and Disability. Leonesio [1993a] notes that these interactions between decisions are consistent with a life-cycle model of economic behavior; such observations emphasize the importance of dynamic decision processes.

One impediment to fully modelling all the interactions between these many factors in the past has been computational limitation. However, computers are becoming increasingly faster, and with this, models are increasing in complexity. With improved technology comes an ability to accommodate the proliferation of choices in our economic models. Besides choosing a retirement date, many individuals are faced with having to decide how to receive a pre- or post-retirement distribution (annuity or some other form); these decisions might be modelled in a simultaneous decision framework.

Virtually the only attempt to model all interactions is Rust [1989], where an astounding quantity of (admittedly discrete) transitions are modelled. Given that data often are in discrete units, however, this does not seem like an unrealistic approximation, even though behavioral decisions are more accurately modelled as continuous processes. In addition, Rust specifies dynamic processes for marital status, employment, health status, wealth, etc. The problem is the computational burden involved. This is a problem with 
dynamic programming models in general, where, without simplifying assumptions, the number of nodes in the decision tree increases exponentially with the number of time periods (i.e., nodes $=C^{T}$, where $C$ is the number of choices and $T$ is the number of time periods). Future models, therefore, must focus on adequately modelling transitional behavior and conditional probabilities, where the conditioning information set incorporates the complete history of choices available to the individual. The emphasis should be on this as a means of reducing computational time and more closely approximating actual behavior.

Still, there are a number of limitations to the model in Rust [1989]; these are recognized by Rust himself and also outlined in Burtless [1989] and Rust and Phelan [1993]. Many modelling limitations are the fault of data limitations; in Rust's case, this is inadequate information on pensions and caregiving responsibilities and computational burden. Burtless [1989] notes that most studies examine a single issue; more advanced ones consider a subset of the determinants, allowing for some interaction. Rust [1989] has laid out a comprehensive framework which, in principle, allows assessment of all determinants at once. Of course it too is limited by data, computational burden, and assumptions about stochastic processes which describe the evolution of these factors over time. However, it defines the state-of-the-art in terms of what models should ultimately hope to achievea way of mimicking behavior and mirroring the dynamic nature of decision making.

Another form of endogeneity arises when trying to draw inferences regarding policy changes. To the extent that policy and behavior are jointly determined, parameter estimates obtained from a base model under the current policy regime will not accurately reflect effects in an alternative policy state (see Lucas [1981] and discussion therein).

A final form of endogeneity is sample selection. As discussed in each of the sections above, heterogeneity between a sample population and a reference population will render inferences useless. It is important, therefore, to assess the extent of sample selection and its role in affecting inferences and, if necessary, to attempt to correct biases that may arise. 


\section{Uncertainty}

Few models of retirement behavior have allowed for uncertainty in the specification. Even dynamic models such as Gustman and Steinmeier [1986] assume perfect markets and Stock and Wise [1990a,b] assume perfect foresight in imputed earnings computations. Capturing individual uncertainty (including, but not limited to, modelling expectations, as discussed above), such as the probability of finding a new job or of qualifying for disability insurance is crucial to understanding and modelling behavior. It is also important in dynamic models to control for aggregate uncertainty; in the case of pension plans this could include the financial condition of the firm or the termination of the plan. At more macroeconomic levels, this includes concerns over solvency of public programs such as Social Security, Disability, and Medicare.

One way to incorporate uncertainty into dynamic models is by simulation methods such as those in Keane and Wolpin [1994]. This usually requires specifying an error distribution. When individual-specific correlation is introduced into a dynamic programming specification, a multidimensional integral results, often rendering the model intractable. ${ }^{9}$ Keane and Wolpin use Monte Carlo integration to approximate the integral and suggest that such approximations perform well, both in being able to mimic behavior and in terms of providing plausible structural parameter estimates.

\section{Data Issues}

Rust [1989] raises the issue of approximating continuous processes with discrete variables, distinguishing between the discrete employment state and the continuous employment decision (p. 371). Similarly, application for disability benefits (like SS) is dichotomous, but the decision process is not. It is therefore important to consider how to model the transition to disability, perhaps even a more continuous process than the

9 A multidimensional integral will also arise with a multichotomous decision variable. Keane and Wolpin provide a 4-dimensional example, where an individual's labor force participation decision is between two occupations, schooling, and staying home. 
transition to retirement. Discretizing health status is equally tricky. In general, models need to accommodate both decision variables, which are continuous, and associated behavioral states, which are discrete. Current research still does not adequately model both jointly.

Many of the shortcomings of previous literature, as well as the failure to model adequately the multiple factors influencing the retirement decision, stem from insufficient datasets. Two of the most promising datasets for future researchers are the Health and Retirement Survey (HRS) and the Asset and Health Dynamics Among the Oldest Old $(A H E A D)$ survey.

Improving data accuracy and eliminating systematic biases should be a top priority. Evidence in Parsons [1991b] suggests that workers are reluctant to admit they have applied for disability insurance; similarly, virtually all surveys of income exhibit signs of income underreporting by respondents. Linkages across datasets improve the ability to check responses for consistency and accuracy.

New techniques were employed to improve the response rate for the HRS. Besides asking the same questions a number of times with slightly different phrasing, interviewers also used unfolding brackets and card brackets to encourage responses. Juster and Smith [1994] argue that these techniques provide significantly more accurate imputations of financial variables, such as non-housing wealth. They also propose using an "optimal brackets" method of threshold determination, where the optimality criterion is to maximize the between group sum of squares. They find that asset imputations "are almost twice as large as those currently being obtained in SIPP"; this suggests that previous studies that have used SIPP's imputations have understated non-housing wealth by 22 percent. Extending the bracketing techniques of Juster and Smith [1994] to other survey datasets still in progress is another dimension in which we can go to improve the quality of data for studying questions related to retirement and retirement income. 


\section{E. Other Concerns}

Returning to concerns over income inadequacy of the elderly and projected funding inadequacy among government programs such as Social Security, Medicare, and Disability Insurance, the interactions among decisions related to retirement behavior and income suggest that inadequacy may affect an increasingly concentrated proportion of the population. If current demographic trends continue and policy emphasis does not address their needs, this population will most likely be elderly women living alone. Correlations among the variates considered in this paper point to the development of a bi-modal distribution of elderly (Reno [1994]) - those that were high wage earners in their worklives and therefore have adequate retirement income (in the form of pension benefits, a post-retirement job, low medical expenditures, and high levels of savings) and those that were not (having less attachment to the labor force, lower probability of a pension, and being in poorer health). 


\section{References}

Allen, Steven G., Robert L. Clark, and Ann A. McDermed [1993], "Pensions Bonding, and Lifetime Jobs," Journal of Human Resources 28(3), pp.463-481.

Anderson, Kathryn H., Richard V. Burkhauser, and Joseph F. Quinn [1986], "Do Retirement Dreams Come True? The Effect of Unanticipated Events on Retirement Plans," International Labor Relations Review 39, 518-526.

Auerbach, Alan J., Laurence J. Kotlikoff, and David N. Weil [1992], "The Increasing Annuitization of the Elderly - Estimates and Implications for Intergenerational Transfers, Inequality, and National Saving," NBER Working Paper \#4182.

Ausink, John A. [1991], "The Effect of Changes in Compensation on a Pilot's Decision to Leave the Air Force," unpublished Ph.D. dissertation, Harvard University.

Ausink, John A., and David A. Wise [1993], "The Military Pension, Compensation, and Retirement of U.S. Air Force Pilots," NBER Working Paper \#4593.

Bai, Jushan, Robin L. Lumsdaine, and James H. Stock [1994], "Testing For and Dating Breaks in Integrated and Cointegrated Time Series," manuscript.

Barron, J.M., and A. Fraedrich. 1994. "The Implications of Job Matching for Retirement Health Insurance and Leave Benefits," Applied Economics 26, 425-435.

Beller, Daniel J., and Helen H. Lawrence [1992], " Trends in Private Pension Plan Coverage," in J.A. Turner and D.J. Beller (eds.), Trends in Pensions 1992. Washington DC: US Government Printing Office.

Berkovec, James and Steven Stern [1991], "Job Exit Behavior of Older Men," Econometrica 59(1), pp. 189-210..

Bernheim, B. Douglas [1989], "The Timing of Retirement: A Comparison of Expectations and Realizations," in D. Wise (ed.), The Economics of Aging. Chicago: University of Chicago Press.

[1994], "Do Households Appreciate Their Financial Vulnerabilities? An Analysis of Actions, Perceptions, and Public Policy," unpublished manuscript, Stanford University. 
Bernheim, B. Douglas, and Lawrence Levin [1989], "Social Security and Personal Saving: An Analysis of Expectations," AEA Papers and Proceedings, 97-102.

Blank, Rebecca M. [1994], "The Dynamics of Part-Time Work," NBER Working Paper \#4911.

Bondar, Joseph [1993], "Beneficiaries Affected by the Annual Earnings Test, 1989," Social Security Bulletin 56(1), 20-28.

Bound, John [1989], "The Health and Savings of Rejected Disability Insurance Applicants," American Economic Review 79, 482-503.

Bound, John, and Timothy Waidmann [1992], "Disability Transfers, Self-Reported Health and the Labor Force Attachment of Older Men: Evidence from the Historical Record," Quarterly Journal of Economics 107, 1393-1419.

Burkhauser, Richard V., J.S. Butler, Yang Woo Kim, and George A. Slotsve [1992], "Modeling Application for Disability Insurance as a Retirement Decision: A Hazard Model Approach using Choice-Based Sampling," The Maxwell School of Citizenship and Public Affairs, Syracuse University, Policy Series Paper No. 3.

Burtless, Gary [1989], "Comment," in D. Wise (ed.), The Economics of Aging. Chicago: University of Chicago Press.

Burtless, Gary T., and Robert A. Moffitt [1984], "The Effect of Social Security Benefits on the Labor Supply of the Aged," in H.J. Aaron and G. Burtless (eds.), Retirement and Economic Behavior. Washington, DC.: Brookings Institution.

Burtless, Gary T., and Robert A. Moffitt [1985], "The Joint Choice of Retirement Age and Postretirement Hours of Work," Journal of Labor Economics 3 (2): 209-236.

Clark, Robert L., Stephan F. Gohmann, and Ann A. McDermed [1988], "Declining Use of Defined Benefit Pension Plans: Is Federal Regulation the Reason?", unpublished manuscript.

Commerce Clearing House, Inc. [1993], 1999 Medicare Explained. Chicago: Commerce Clearing House, Inc. 
Congressional Budget Office [1993], Baby Boomers in Retirement: An Early Perspective. Washington: U.S. Government Printing Office.

Daula, T.V., and R.A. Moffitt [1991], "Estimating a Dynamic Programming Model of Army Reenlistment Behavior," in C.L. Gilroy, D.K. Horne, and D. A. Smith (eds.), Military Compensation and Personnel Retention: Models and Evidence. Alexandria, VA: U.S. Army Research Institute for the Behavioral and Social Sciences.

Day, Christine L. [1993], "Public Opinion Toward Costs and Benefits of Social Security and Medicare," Research on Aging 15(3), 279-298.

Economic Report of the President [1993]. Washington, D.C.: US Government Printing Office.

Employee Benefit Plan Review [1994a], March, 36-49.

$-[1994 \mathrm{~b}]$, June, 44-59.

Even, William E., and David A. Macpherson [1994], "Gender Differences in Pensions," Journal of Human Resources 29(2), 555-587.

Feldstein, Martin, and Andrew Samwick [1992], "Social Security Rules and Marginal Tax Rates," NBER Working Paper \#3962.

Ferber, Marianne A. [1993], "Women's Employment and the Social Security System," Social Security Bulletin 56(3), 33-55.

Fields, Gary S., and Olivia S. Mitchell [1984]. Retirement, Pensions, and Social Security. Cambridge, MA: MIT Press.

General Accounting Office [1989]. Private Pensions: Plan Provisions Differ Between Large and Small Employers, GAO/HRD-89-105BR. Washington, DC: United States General Accounting Office.

- [1990], "Equity Issues in a Changing Retirement System," presentation at the Gerontological Society of America annual meetings.

Gordon, Roger, and Alan Blinder [1980], "Market Wages, Reservation Wages, and Retirement Decisions," Journal of Public Economics 14 (2), 277-308. 
Grad, Susan [1994]. Income of the Population 55 or Older, 1992. SSA Publications No. 13-11871. Washington DC: US Government Printing Office.

Gruber, Jonathan, and Brigitte C. Madrian [1993a], "Health Insurance Availability and the Retirement Decision, NBER Working Paper \#4469.

[1993b], "Health Insurance and Early Retirement: Evidence from the Availability of Continuation Coverage," NBER Working Paper \#4594.

Gustman, Alan L., Olivia S. Mitchell, and Thomas L. Steinmeier [1994] "Retirement Research using the Health and Retirement Survey," NBER Working Paper \#4813.

Gustman, Alan L., and Thomas L. Steinmeier [1986], "A Structural Retirement Model," Econometrica 54 (3), 555-584.

[1991], "Changing the Social Security Rules for Work After 65," International Labor Relations Review 44(4), 733-745.

- [1993a], "Employer Provided Health Insurance and Retirement Behavior," NBER Working Paper \#4307.

- [1993b], "Pension Portability and Labor Mobility: Evidence from the Survey of Income and Program Participation," Journal of Public Economics 50, 299-323.

Hambor, J.C. [1992], "The Role of Economic Factors in the Decline of the DI Trust Fund," U.S. Department of the Treasury working paper.

Hardy, Melissa A. [1991], "Employment After Retirement: Who Gets Back In?" Research on Aging 13(3), 267-288.

Haveman, Robert, Philip deJong, and Barbara L. Wolfe [1991], "Disability Transfers and the Work Decision of Older Men," Quarterly Journal of Economics 106, 939-949.

Haveman, Robert, and Barbara L. Wolfe [1984], "The Decline in Male Labor Force Participation: Comment," Journal of Political Economy 92(3), 532-541.

- [1989], "The Economic Well-Being of the Disabled: 1962-84," Journal of Human Resources XXV(1), 32-54. 
Hayward, Mark D., Melissa A. Hardy, and Mei-Chun Chiang [1990], "Work After Retirement: The Experiences of Older Men in the U.S.," manuscript.

Hewitt Associates [1990]. Salaried Employee Benefits Provided by Major US Employers in 1990. Lincolnshire, IL: Hewitt Associates.

Hill, Martha S., Beth J. Soldo, and Wei Li [1993], "Intergenerational Transfers and Labor Supply: Preliminary Evidence from the HRS," Health and Retirement Study Working Paper Series, Paper No. 94-009.

Holtz-Eakin, Douglas, John R. Penrod, and Harvey S. Rosen [1994], "Health Insurance and the Supply of Entrepreneurs," NBER Working Paper \#4880.

Honig, Marjorie, and Cordelia Reimers [1989], "Is it Worth Eliminating the Retirement Test?," American Economic Review, 103-107.

Hurd, Michael [1993], "The Effect of Labor Market Rigidities on the Labor Force Behavior of Older Workers," NBER Working Paper \#4462.

[1994a], "The Economic Status of the Elderly in the United States," in D. Wise (ed.) Aging in the United States and Japan: Economic Trends, Chicago: University of Chicago Press.

-_ [1994b], "The Effects of Demographic Trends on Consumption, Saving and Government Expenditures in the U.S.," unpublished manuscript, Department of Economics, SUNY.

Hurd, Michael D., and Kathleen McGarry [1993a], "The Relationship between Job Characteristics and Retirement," NBER Working Paper \#4558.

- [1993b], "Evaluation of Subjective Probability Distributions in the HRS," NBER Working Paper \#4560.

Ippolito, Richard [1985], "The Labor Contract and True Economic Pension Liabilities," American Economic Review 75(5), 1031-1043.

Juster, F. Thomas, and James P. Smith [1994], "Improving the Quality of Economic Data: Lessons from the HRS," unpublished manuscript, University of Michigan. 
Karoly, Lynn A., and Jeannette A. Rogowski [1993], "The Effect of Health Insurance on the Decision to Retire," manuscript.

Kasper, Judith D. [1988]. Aging Alone: Profiles and Projections. Baltimore, MD: The Commonwealth Fund Commission on Elderly People Living Alone.

Keane, Michael P., and Kenneth I. Wolpin [1994], "The Solution and Estimation of Discrete Choice Dynamic Programming Models by Simulation and Interpolation: Monte Carlo Evidence," Federal Reserve Bank of Minneapolis, Staff Report 181.

Kingson, Eric [1992]. The Diversity of the Baby Boom Generation: Implications for Their Retirement Years. Washington, D.C.: American Association of Retired Persons.

Klerman, Jacob A. [1992], "How Long is a Spell Without Health Insurance?", manuscript.

Korczyk, Sophie M. [1992], "Gender and Pension Coverage," in J.A. Turner and D.J. Beller (eds.), Trends in Pensions 1992. Washington DC: US Government Printing Office.

Kotlikoff, Laurence J., and David A. Wise [1985], "Labor Compensation and the Structure of Private Pension Plans: Evidence for Contractual versus Spot Labor Markets," in D. Wise (ed.), Pensions, Labor, and Individual Choice. Chicago: University of Chicago Press. -[1987], "The Incentive Effects of Private Pension Plans," in Z. Bodie, J. Shoven, and D. Wise (eds.), Issues in Pension Economics. Chicago: University of Chicago Press.

Lazear, Edward P. [1979], "Why is there Mandatory Retirement?," Journal of Political Economy 87, 1261-64.

Lazear, Edward P., and Robert Moore [1988], "Pensions and Turnover," in Z. Bodie, J. Shoven, and D. Wise (eds.), Pensions in the US Economy. Chicago: University of Chicago Press.

Leonesio, Michael V. [1990], "The Effects of the Social Security Earnings Test on the Labor-Market Activity of Older Americans: A Review of the Evidence" Social Security Bulletin 53(5), 2-21. 
[1993a], "Social Security and Older Workers," Social Security Bulletin 56(2), 4757.

[1993b], "Social Security and Older Workers," in O. Mitchell (ed.), As the Workforce Ages. Ithaca, NY: ILR Press.

Lewin-VHI [1994]. Labor Market Conditions, Socioeconomic Factors and the Growth of Applications and Awards for SSDI and SSI Disability Benefits. Fairfax, VA: LewinVHI.

Lingg, Barbara A. [1990], "Women Beneficiaries Aged 62 or Older, 1960-1988," Social Security Bulletin 53(7), 4.

Lucas, Robert E., Jr. [1981]. Studies in Business Cycle Theory. Cambridge, MA: MIT Press.

Lumsdaine, Robin L., James H. Stock, and David A. Wise [1990], "Efficient Windows and Labor Force Reduction," Journal of Public Economics 43, 131-159.

_[1991], "Windows and Retirement," Annales d'Économie et de Statistique 20/21, 219-242.

[1992], "Three Models of Retirement: Computational Complexity versus Predictive Validity," in D. Wise (ed.), Topics in the Economics of Aging. Chicago: University of Chicago Press.

_[1993] "Why are Retirement Rates so High at Age 65?" manuscript.

[1994a], "Pension Plan Provisions and Retirement: Men \& Women, Medicare and Models," in D. Wise (ed.), Studies in the Economics of Aging. Chicago: University of Chicago Press.

[1994b] "Retirement Incentives: The Interaction Between Employer-Provided Pensions, Social Security, and Retiree Health Benefits," NBER Working Paper \#4613.

Lumsdaine, Robin L., and David A. Wise [1994], "Aging and Labor Force Participation: A Review of Trends and Explanations," in D. Wise (ed.) Aging in the United States and Japan: Economic Trends, Chicago: University of Chicago Press. 
Luzadis, Rebecca A., and Olivia S. Mitchell [1990], "Explaining Pension Dynamics," Journal of Human Resources XXVI(4), 679-703.

Macpherson, David A. [1992], "Employer-provided Retiree Health Insurance: Who is Covered?," Economics Letters 39, 95-99.

Madrian, Brigitte C. [1993], "Post-Retirement Health Insurance and the Decision to Retire," manuscript.

Mehdizadeh, Shahla A., and Rebecca A. Luzadis [1994], "The Effect of Job Mobility on Pension Wealth," The Gerontologist 34(2), 173-179.

Mitchell, Olivia S. [1989],“

- [1991], "Social Security Reforms and Poverty Among Older Dual-earner Couples," Journal of Population Economics 4, 281-293.

- [1992], "Trends in Pension Benefit Formulas and Retirement Provisions," in J.A. Turner and D.J. Beller (eds.) Trends in Pensions 1992. Washington DC: US Government Printing Office.

Parnes, Herbert S., and David G. Sommers [1994], "Shunning Retirement: Work Experience of Men in Their Seventies and Early Eighties," Journal of Gerontology 49(3), S117-S124.

Parsons, Donald O. [1980], "The Decline in Male Labor Force Participation," Journal of Political Economy 88(1), 1117-134.

[1984], "Disability Insurance and Male Labor Force Participation: A Response to Haveman and Wolfe," Journal of Political Economy 92(3), 542-549.

[1991a], "The Health and Earnings of Rejected Disability Insurance Applicants: Comment," American Economic Review 81, 1419-1426.

- [1991b], "Self-Screening in Targeted Public Transfer Programs," Journal of Political Economy 99(4), 859-876.

[1991c], "The Decline in Private Pension Coverage in the United States," Economics Letters 36, 419-423. 
Pavalko, Eliza K., Glen H. Elder, Jr., and Elizabeth C. Clipp [1993], "Worklives and Longevity: Insights from a Life Course Perspective," Journal of Health and Social Behavior 34, 363-380.

Perrachi, Franco, and Finis Welch [1994], "Trends in Labor Force Transitions of Older Men and Women," Journal of Labor Economics 12(2), 210-242.

Pienta, Amy M., Jeffrey A. Burr, and Jan E. Mutchler [1993], "Women's Labor Force Participation in Later Life: The Effects of Early Work and Family Experiences," manuscript, SUNY Buffalo.

Pozzebon, Silvana, and Olivia S. Mitchell [1989], "Married Women's Retirement Behavior," Journal of Population Economics 2, 39-53.

Quadagno, Jill S., and Melissa Hardy [1991], "Regulating Retirement Through the Age Discrimination in Employment Act," Research on Aging 13(4), 470-475.

Quinn, Joseph F., Richard V. Burkhauser, and Daniel A. Myers [1990]. Passing the Torch: The Influence of Financial Incentives on Work and Retirement. Kalamazoo, MI: W.E. Upjohn Institute on Employment Research.

Quinn, Joseph F. and Richard V. Burkhauser [1992], "Retirement and the Labor Force Behavior of the Elderly," manuscript.

Radner, Daniel B. [1993a], "An Assessment of the Economics Status of the Aged," in Studies in Income Distribution, No. 16. Washington, DC: US Department of Health and Human Services.

- [1993b], "Economic Well-Being of the Old Old: Family Unit Income and Household Wealth," Social Security Bulletin 56(1), 3-19.

Reimers, Cordelia, and Marjorie Honig [1992], "Labor Supply Differences Between Older Men and Women: Evidence from Re-Entry Behavior," manuscript.

[1993], "The Perceived Budget Constraint under Social Security: Evidence from Re-entry Behavior," Journal of Labor Economics 11(1), 184-204.

Reno, Virginia P. [1993], "The Role of Pensions in Retirement Income: Trends and Questions," Social Security Bulletin 56(1), 29-43. 
Ruhm, Christopher J. [1990], "Bridge Jobs and Partial Retirement," Journal of Labor Economics 8(4), 482-501.

[1994], "Do Pensions Increase the Labor Supply of Older Men?", NBER Working Paper \#4925.

Rust, John [1989], "A Dynamic Programming Model of Retirement Behavior," in D. Wise (ed.), The Economics of Aging. Chicago: University of Chicago Press.

[1994], "Comment," in D. Wise (ed.), Studies in the Economics of Aging. Chicago: University of Chicago Press.

Rust, John, and Christopher Phelan [1993], "How Social Security and Medicare Affect Retirement Behavior in a World of Incomplete Markets," unpublished manuscript, University of Wisconsin.

Samwick, Andrew A. [1994], "The Joint Effect of Social Security and Pensions on the Timing of Retirement: Some New Evidence," unpublished manuscript, Dartmouth College.

Scott, Frank, Mark Berger, and John Garen [1992], "Do Health Insurance Costs and Non-Discrimination Policies Reduce the Job Opportunities of Older Workers?", manuscript.

Smith, James P. [1994], "Comment," in D. Wise (ed.), Studies in the Economics of Aging. Chicago: University of Chicago Press.

Stern, Steven [1988], "Measuring the Effect of Disability on Labor Force Participation," Journal of Human Resources XXIV(3), 361-395.

Stewart, Jay [1995], "Do Older Workers Respond to Changes in Social Security Benefits? A Look at the Time Series Evidence," unpublished manuscript.

Stock, James H., and David A. Wise [1990a], "Pensions, the Option Value of Work, and Retirement," Econometrica 58(5), 1151-1180.

- [1990b] "The Pension Inducement to Retire: An Option Value Analysis," in D. Wise (ed.), Issues in the Economics of Aging. Chicago: University of Chicago Press.

US Bureau of the Census [1992]. Statistical Abstract of the United States: 1992. 
US Department of Labor [1992]. Employee Benefits in a Changing Economy: A BLS Chartbook. Washington, DC: US Government Printing Office.

US Department of Labor [1994]. Pension Coverage Issues for the 'g0s. Washington, DC: US Government Printing Office.

US National Center for Health Statistics [1990]. Vital Statistics of the United States, 1990. Hyattsville, MD: US Department of Health and Human Services.

Venti, Steven F., and David A. Wise [1992], "Government Policy and Personal Retirement Saving," in James M. Poterba (ed.), Tax Policy and the Economy 6, Cambridge, MA: MIT Press.

Viscusi, W. Kip [1985], "The Structure of Uncertainty and the Use of Nontransferable Pensions as a Mobility-Reduction Device," in D. Wise (ed.), Pensions, Labor, and Individual Choice. Chicago: University of Chicago Press.

Waidmann, Timothy, John Bound, and Michael Schoenbaum [1995], "The Illusion of Failure: Trends in the Self-Reported Health of the US Elderly," NBER Working Paper \#5017.

Weaver, David A. [1994], "The Work and Retirement Decisions of Older Women: A Literature Review," Social Security Bulletin 57(1), 3-24.

Woods, John R. [1993], "Pension Vesting and Preretirement Lump Sums Among FullTime Private Sector Employees," Social Security Bulletin 56(3), 3-21. 
Table 1. Labor Force Participation Rates

Source: Kingson [1992]].

Table 2. Life Expectancy and Projections among white men and women, age 65 Source: US National Center for Health Statistics [1990], actual, and Hurd [1993], projections.

Table 3. Percentage of Women over Age 62 Receiving Social Security on the Basis of Their Own Work History.

Source: US Dept. of Labor [1994] and Lingg [1990] (primary source).

Table 4. Coverage Rates, Employer-Provided Pensions, 1979-1987.

Source: US Dept. of Labor [1994] and Parsons [1991c].

Table 5. Job Tenure and Pension Coverage of Full-Time Private Sector Workers, By Gender, 1988. Source: Korcyzk [1992], Table 6.11.

Table 6. Earnings Distribution and Pension Coverage Rates Among Full-Time Private Sector Workers, By Gender, 1988. Source: Korcyzk [1992], Table 6.6.

Table 7. Percentage of Working-Age Population Disabled, by Sex, 1962-84. Source: Haveman and Wolfe [1989].

Figure 1. Percent of Persons Below Poverty and Near-Poverty Thresholds, by Age, 1990. Source: Radner [1993].

Figure 2. Percent of the Elderly Living Alone. Source: Kaspar [1988].

Figure 3. Recipients of Social Security Payments. Source: US D of Labor [1992], chart 25.

Figure 4. Average Replacement Rate for Defined Benefit Pension Plan Participants. Source: US Dept. of Labor [1992], chart 20.

Figure 5. Composition of Elderly People Living Alone. Source: Kaspar [1988].

Figure 6. The PIA/Earnings Ratio and the Non-participation Rate of Men 65-69. Source: Stewart [1995].

Figure 7. Age Distribution of the Disability Insured. Source: Lewin-VHI [1994], exhibit IV.A.3.

Figure 8. SSDI Award Rates for Men and Women, Selected Years, 1975-1992. Source: Lewin-VHI [1994], exhibit IV.A.4 and IV.A.5.

Figure 9. Prevalence of Disability in the US, 1981-1990. Source: Lewin-VHI [1994], exhibit IV.D.1.

Figure 10. Nonparticipation in the Labor Force and Social Security Disability Recipiency, Males 45-54, 1947-82. Source: Parsons [1984]. 
Table 1

Labor Force Participation Rates

\begin{tabular}{lllllllllll} 
& \multicolumn{9}{c}{ Men } & \multicolumn{9}{c}{ Women } \\
& $45-54$ & $55-59$ & $60-61$ & $62-64$ & $65+$ & $45-54$ & $55-59$ & $60-61$ & $62-64$ & $65+$ \\
1970 & 94.3 & 89.5 & 82.6 & 69.4 & 26.8 & 54.4 & 50.4 & 41.4 & 32.3 & 9.7 \\
1990 & 90.7 & 79.8 & 68.8 & 46.4 & 16.4 & 71.2 & 55.3 & 42.9 & 30.7 & $\mathbf{8 . 7}$
\end{tabular}

Source: U.S. Bureau of the Census, Statistical Abstract of the United States: 1992 (1992), Table 622.

Table 2

Life Expectancy and Projections among white men and women, age 65

\begin{tabular}{lcccccc} 
& \multicolumn{3}{c}{ Men } & \multicolumn{1}{c}{ Women } \\
Actual & & & & & \\
1980 & & 14.2 & & 18.4 & \\
1990 & & 15.2 & & 19.1 & \\
& & & & & & \\
Projected & I & II & III & II & III \\
2000 & 15.3 & 15.9 & 16.4 & 18.9 & 19.6 & 20.2 \\
2020 & 15.6 & 16.7 & 18.0 & 19.1 & 20.4 & 21.9
\end{tabular}

Source: US National Center for Health Statistics, Vital Statistics of the United States, 1990 (actual), and Hurd [1993] (projections). 
Table 3

PERCENTAGE OF WOMEN OVER AGE 62 RECEMING SOCLL SECURTY ON THE BASAS OF THEAR OWN WOAK HISTORY

\begin{tabular}{lc}
\hline Year & Percent \\
\hline 1960 & 43.3 \\
1970 & 50.6 \\
1980 & 56.9 \\
1988 & 59.7 \\
\hline
\end{tabular}

Source: US Dept. of Labor [1994] and Lingg [1990] (primary source).

Table 4

COVERAGE RATES, EMPLOYER-PROVIDED PENSIONS, 1979-1987

Panel A

Percentage of Civilian Wage and Salary Workers Covered by Pension Plans, Total and by Sex

\begin{tabular}{|c|c|c|c|c|c|c|c|c|c|}
\hline & 1979 & 1980 & 1981 & 1982 & 1983 & 1984 & 1985 & 1986 & 1987 \\
\hline $\begin{array}{l}\text { Total } \\
\text { Male } \\
\text { Female }\end{array}$ & $\begin{array}{l}44.9 \% \\
51.5 \\
37.0\end{array}$ & $\begin{array}{l}44.9 \% \\
51.0 \\
37.5\end{array}$ & $\begin{array}{l}44.3 \% \\
50.1 \\
37.3\end{array}$ & $\begin{array}{l}43.8 \% \\
48.9 \\
37.7\end{array}$ & $\begin{array}{l}43.4 \% \\
48.3 \\
37.7\end{array}$ & $\begin{array}{l}42.4 \% \\
47.1 \\
37.0\end{array}$ & $\begin{array}{l}42.8 \% \\
47.5 \\
37.4\end{array}$ & $\begin{array}{l}42.6 \% \\
47.0 \\
37.6\end{array}$ & $\begin{array}{l}40.8 \% \\
45.1 \\
36.0\end{array}$ \\
\hline
\end{tabular}

Panel B
Percentage of Households with One or More Members Covered by Employer-Provided Pension Plans, Total

\begin{tabular}{lccccccccc} 
& 1979 & 1980 & 1981 & 1982 & 1983 & 1984 & 1985 & 1986 & 1987 \\
\hline Total & $47.1 \%$ & $46.5 \%$ & $45.6 \%$ & $44.7 \%$ & $44.1 \%$ & $43.7 \%$ & $44.1 \%$ & $44.2 \%$ & $42.2 \%$ \\
\hline
\end{tabular}

Source: US Dept. of Labor [ 1994] and Parsons [ 1991c]. 
Table 5

Job Tenure and Penslon Covarage of Full-Time Private Sector Workers, By Gender, 1988

[Peroent]

\begin{tabular}{|c|c|c|}
\hline Years with primery employer & Women & Men \\
\hline \multicolumn{3}{|l|}{ Job tenure } \\
\hline 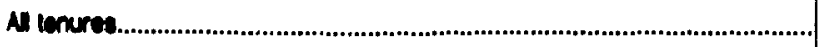 & 100 & 100 \\
\hline Leas than 1 year ........................................................... & 19 & 17 \\
\hline ito 4 years & 37 & 33 \\
\hline 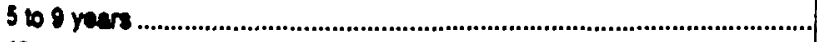 & 18 & 17 \\
\hline 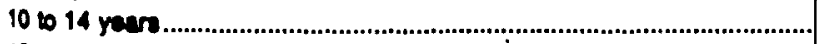 & 10 & 11 \\
\hline 15 to 10 years & 6 & 7 \\
\hline 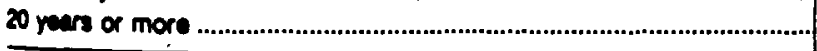 & $\mathbf{5}$ & 11 \\
\hline \multicolumn{3}{|l|}{ Pencion coverege } \\
\hline Al tenures......................................................... & 43 & 50 \\
\hline Leas than 1 year ............................................................... & 13 & 18 \\
\hline 1 to 4 year & 37 & 30 \\
\hline 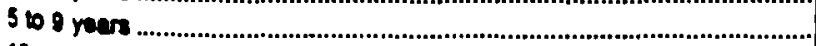 & $\mathbf{8 3}$ & $\mathbf{8 2}$ \\
\hline 10 to 14 years ...................... & 70 & 73 \\
\hline 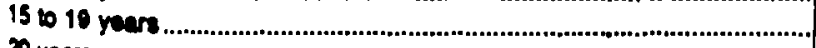 & 72 & 77 \\
\hline 20 years or more ................................... & 75 & 92 \\
\hline
\end{tabular}

Source: Korcyzk [1992], Table 6.11. 
Earnings Distrlbution and Pension Coverage Rates Among Fulk Time Private Sector Workers, By Gender, 1988 "

[Poreent]

\begin{tabular}{|c|c|c|}
\hline Earnings & Women & $\mathrm{Men}$ \\
\hline \multicolumn{3}{|l|}{ Earnings distribution } \\
\hline Total & 100 & 100 \\
\hline 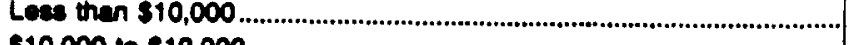 & 23 & 10 \\
\hline$\$ 10,000$ to $\$ 18,990$ & 47 & 31 \\
\hline$\$ 20,000$ to $\$ 29,909$ & 21 & $\mathbf{z}$ \\
\hline 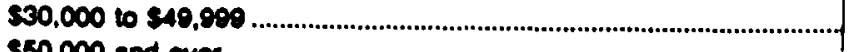 & 9 & 27 \\
\hline 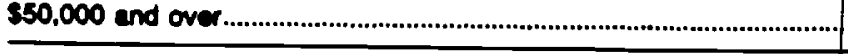 & 1 & 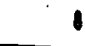 \\
\hline \multicolumn{3}{|l|}{ Pencion coverage rate } \\
\hline 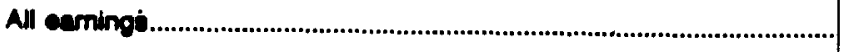 & 43 & 50 \\
\hline Leas then $\$ 10,000$ & 13 & 19 \\
\hline$\$ 10,000$ to $\$ 10,900$ & 48 & $\mathbf{3}$ \\
\hline$\$ 20,000$ to 320,900 & 64 & $\boldsymbol{*}$ \\
\hline$\$ 30,000$ to $\$ 40,800$ & 75 & 11 \\
\hline 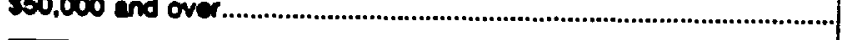 & 77 & $\pi$ \\
\hline
\end{tabular}

Source: Korcyzk [1991], Table 6.6.

Table 7

Percentage of Working-Age Population Disabled, by Sex, 1962-84. Various Years and Sample Size

\begin{tabular}{rrrrrr}
\hline & Male & Female & Total & $\begin{array}{c}\text { Actual } \\
\text { Number } \\
\text { Male }\end{array}$ & $\begin{array}{c}\text { Actual } \\
\text { Number } \\
\text { Female }\end{array}$ \\
\hline 1962 & 9.5 & 4.8 & 7.0 & 218 & 120 \\
1968 & 13.0 & 8.2 & 10.5 & 911 & 746 \\
1973 & 12.8 & 9.3 & 11.0 & 1434 & \\
1976 & 14.6 & 7.5 & 10.9 & 491 & 304 \\
1980 & 11.9 & 9.6 & 10.7 & 501 & 416 \\
1982 & 10.6 & 9.1 & 9.6 & 441 & 380 \\
1984 & 10.5 & 8.6 & 9.5 & 461 & 454 \\
\hline
\end{tabular}

Note: Calculations by the authors from CPS data for various years; see text.

Source: Haveman and Wolfe [1989]. 
Figure 1

Percent of persons below poverty and near-poverty thresholds, by age, 1990

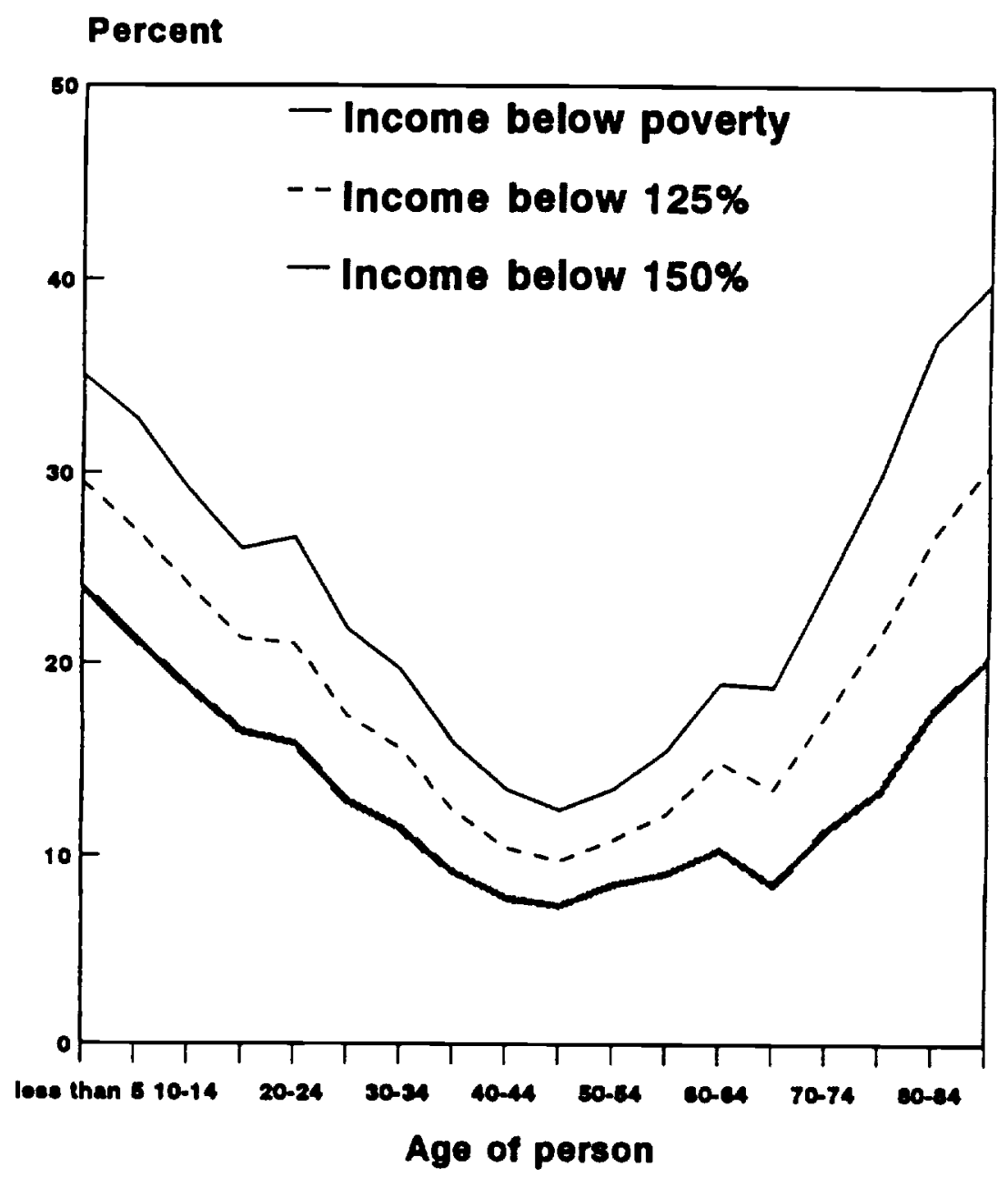

Source: Radner [1993]. 


\section{Figure 2}

Elderly women are more likely to live alone than are elderly men.

\section{PERCENT LIVING ALONE}

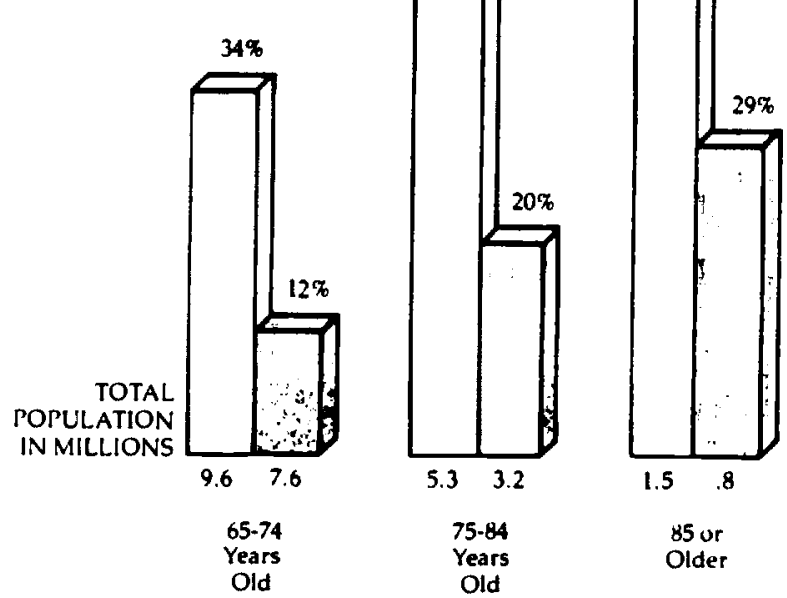

Source: Kaspar [1988]. 
Figure 3

\section{Recipients of Social Security} payments, $1940-90$

Beneficiaries (in millions)

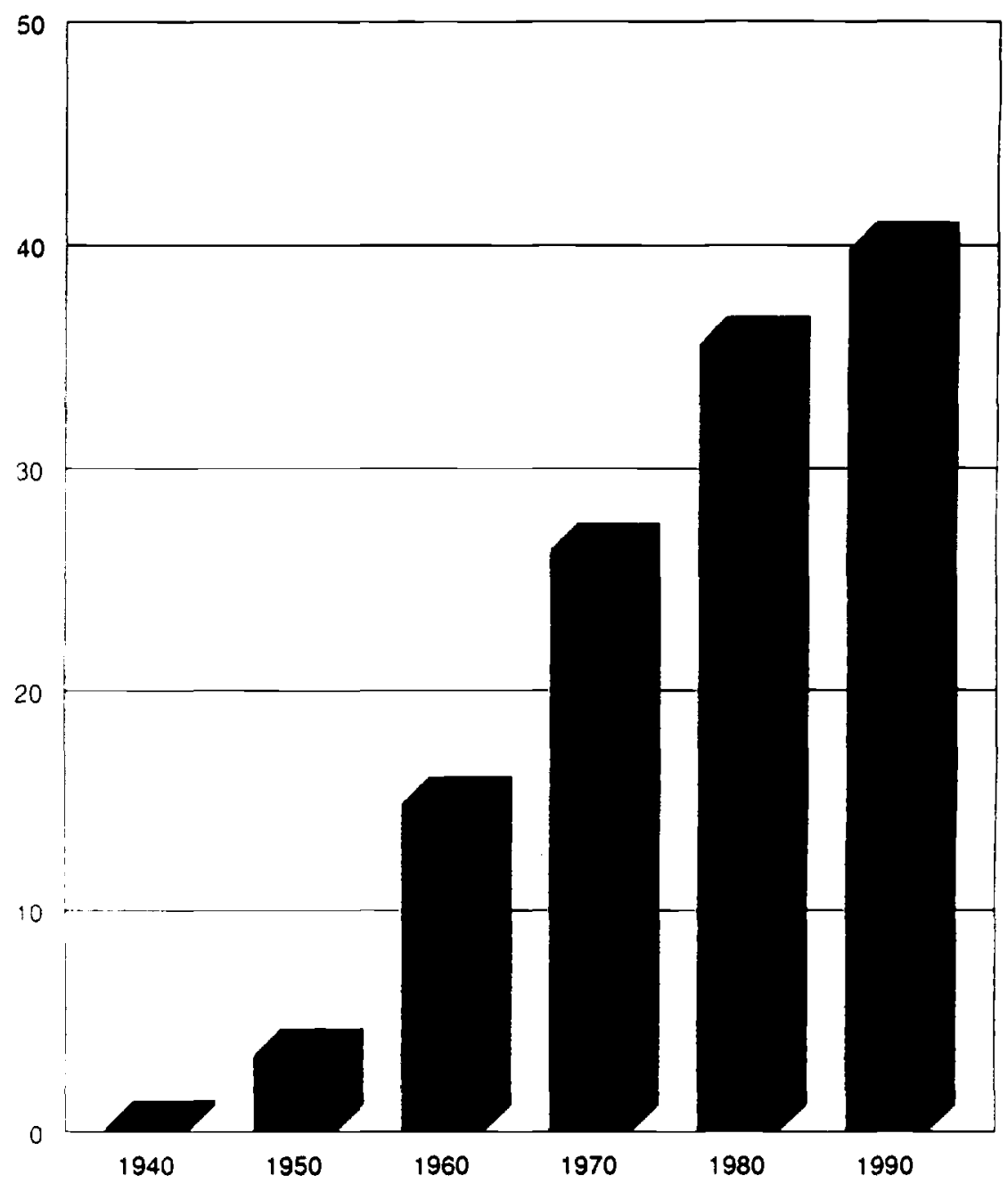

Source: US Dept. of Labor [1992], chart 25. 


\section{Average replacement rate for defined benefit pension plan participants, medium and large private establishments, 1989}

Replacement rate

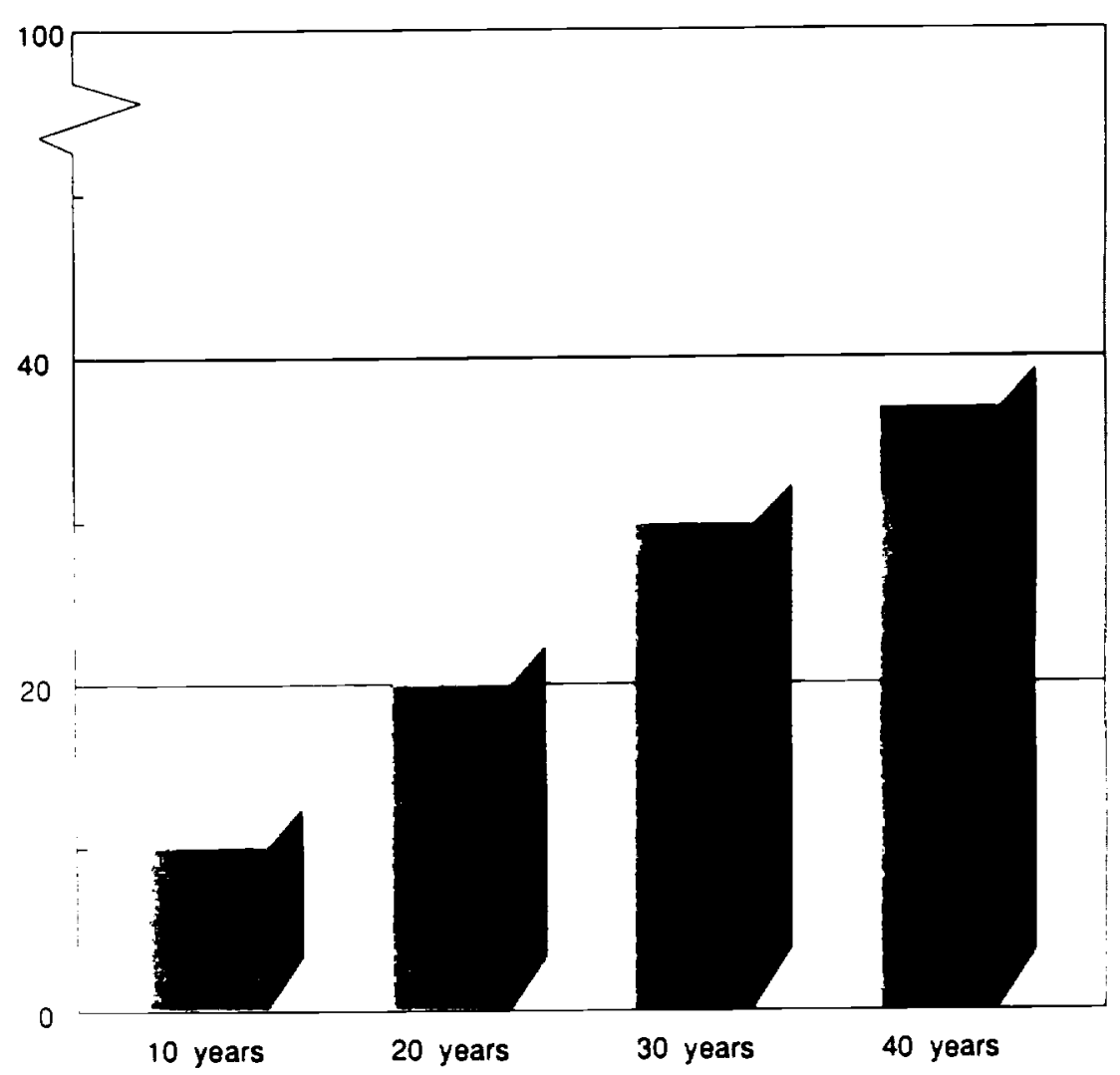

Years of plan participation

Note: Calculations based on retirement at age 65 with annual salary of $\$ 35,000$ in final year.

Source: US Dept. of Labor [1992], chart 20. 
Figure 5

Composition of Elderly People Living Alone

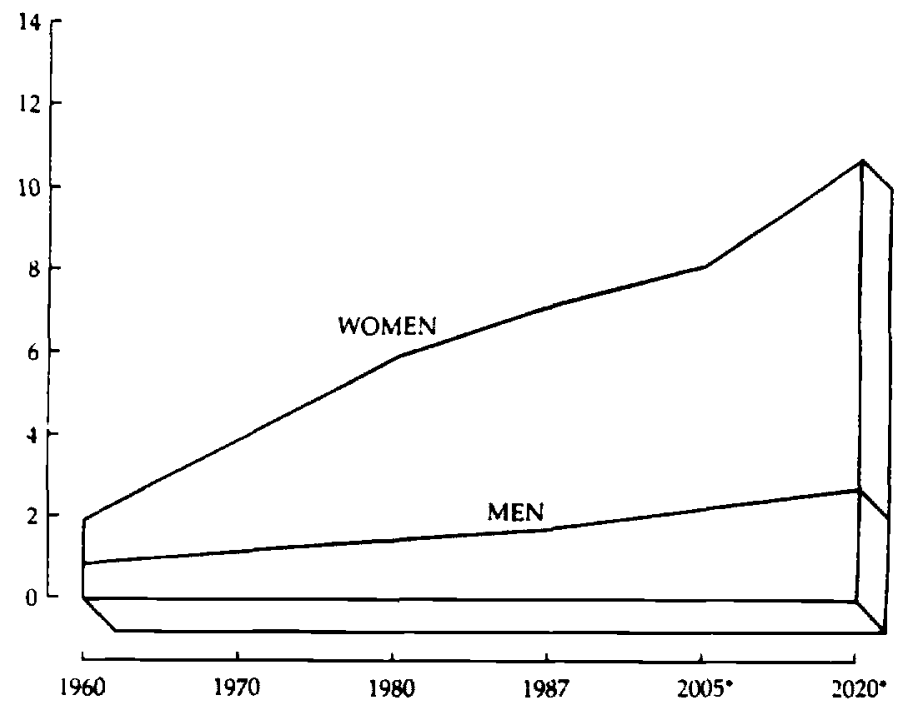

ELDERLY PEOPLE LIVINC ALONE (MILLIONS)

Source: Kaspar [1988]. 


\section{Figure 6}

The PIA/Earnings Ratio and the Non-participation Rate of Men 65-69

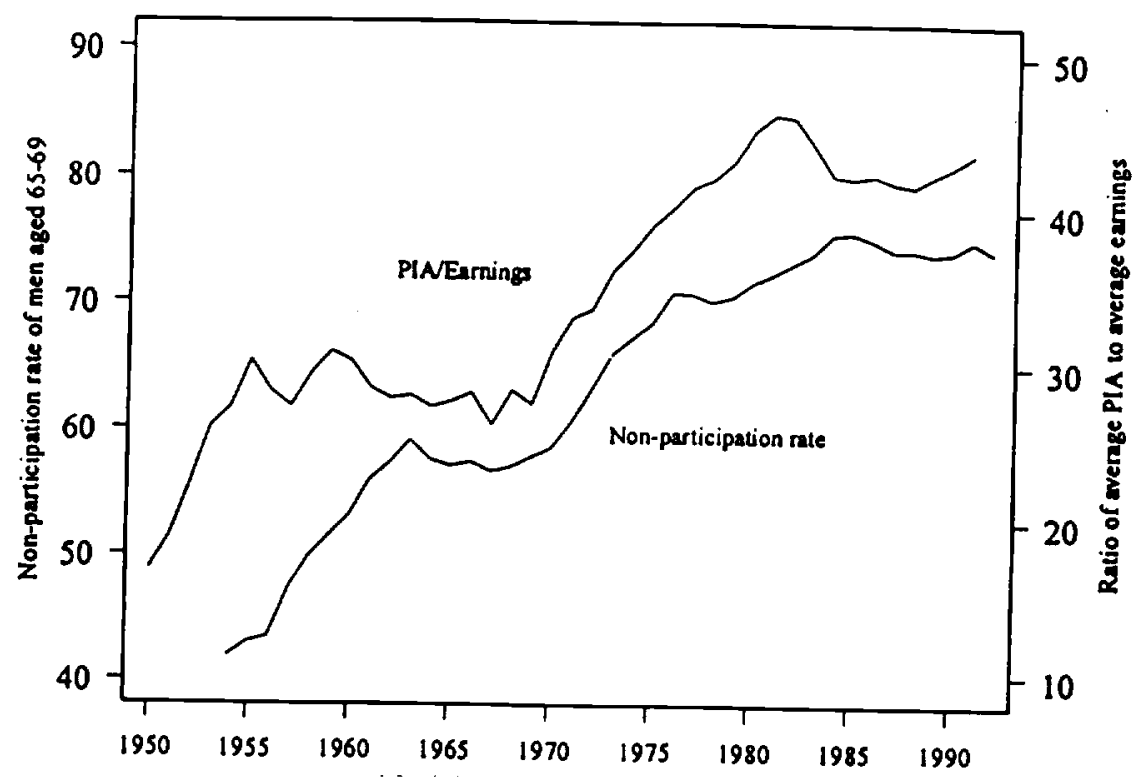

Source: Stewart [1995]. 
Figure 7

Age Distribution of the Disability Insured

Number of Persons Insured for Disability by Five-Year Age Cohort, Selected Years, 1980-2000

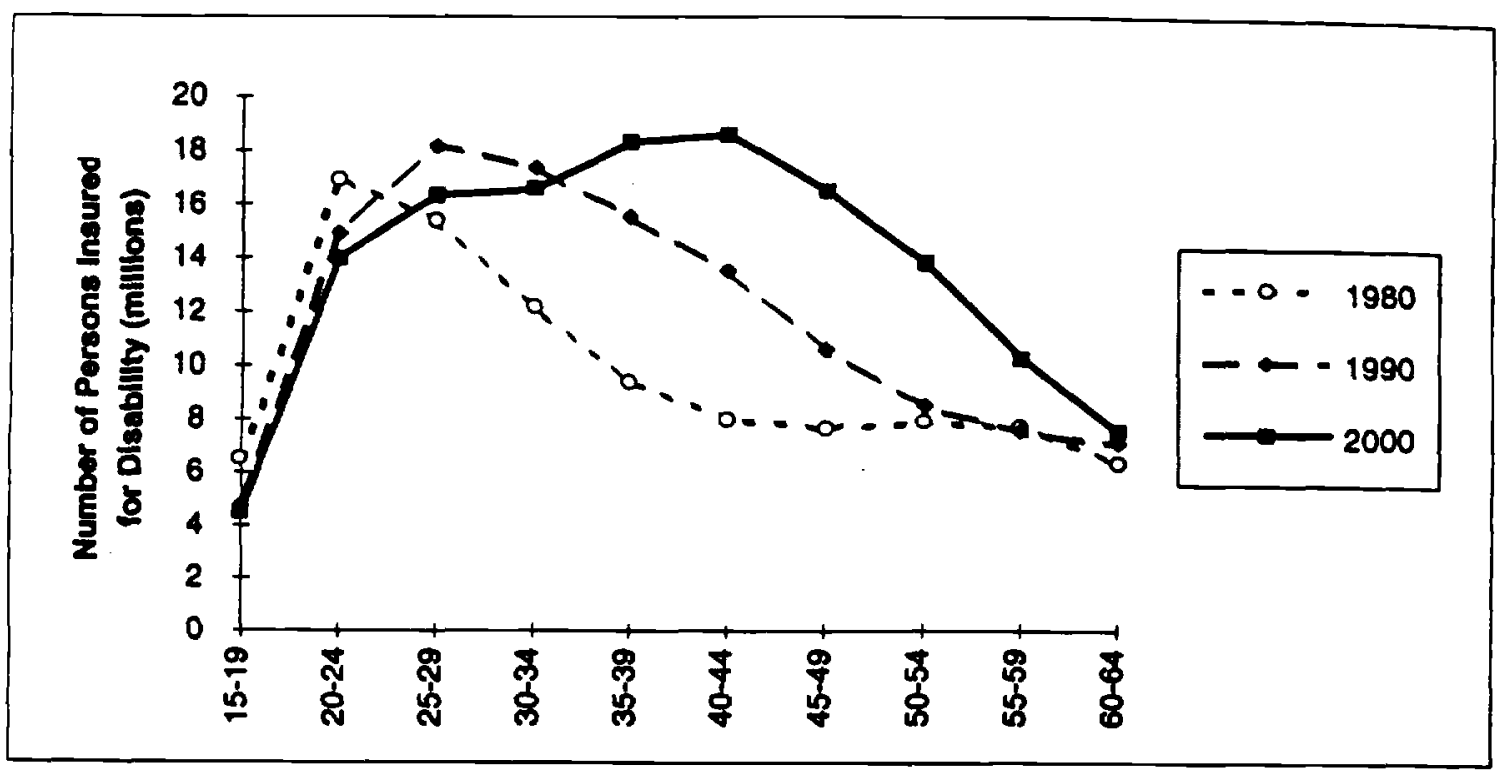

Source: Lewin-VHI [1994], exhibit IV.A.3. 
Figure 8

SSDI Award Rates for Men, Selected Years, 1975-1992

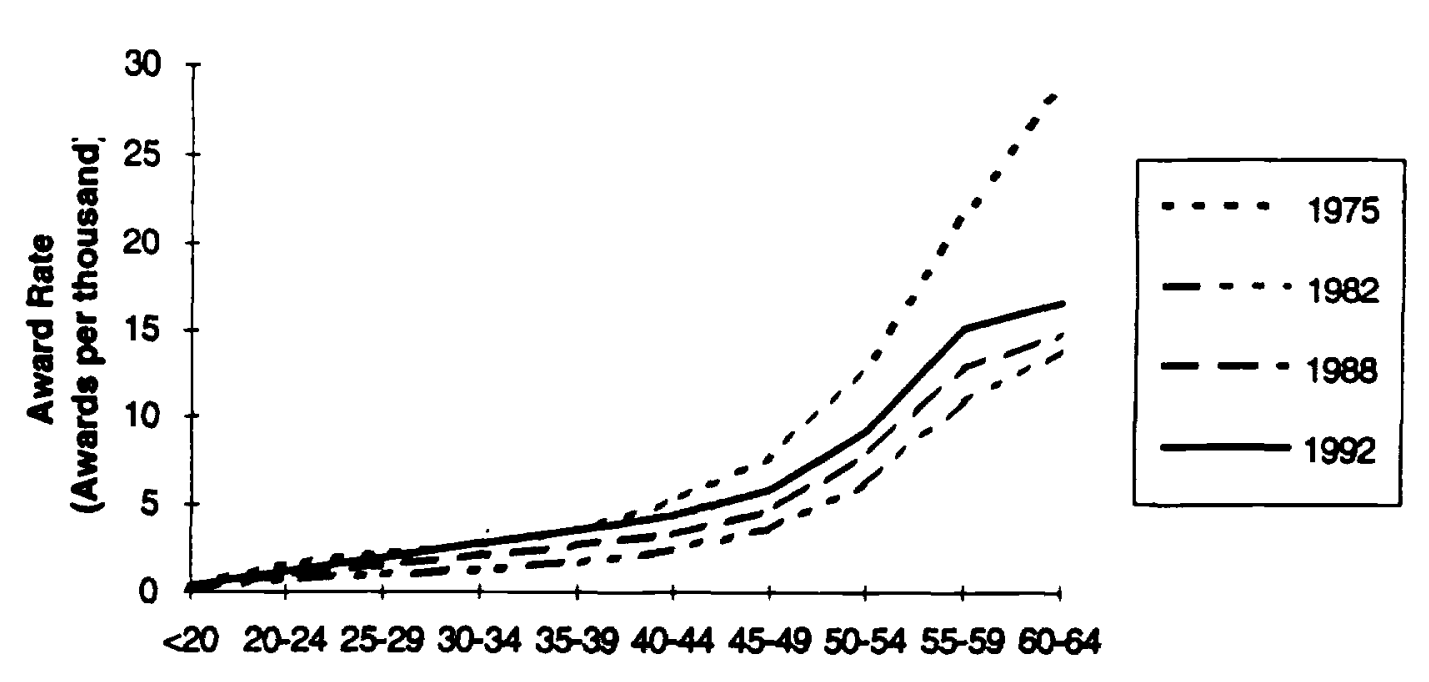

- Award rates for men are calculated as the number of awards to men divided by thousands of men insured for disability.

SSDI Award Rates for Women, Selected Years, 1975-1992

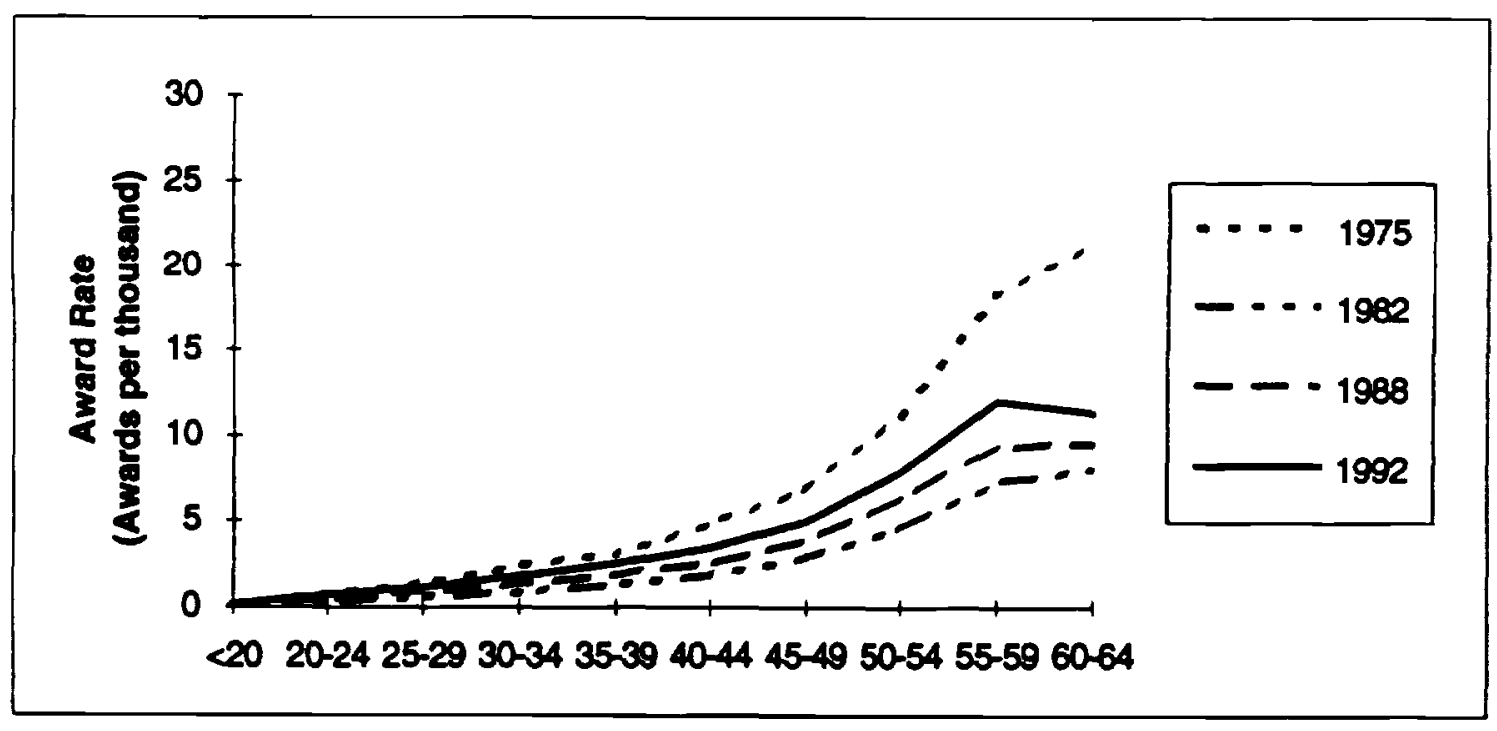

- Award rues for women are calculated as the number of awards to women divided by thousands of womea insured for disability.

Source: Lewin-VHI [1994], exhibit IV.A.4 and IV.A.5. 


\section{Figure 9}

The Prevalence of Disability in the U.S. among Working Age Persons from 1981 to 1990 as Measured by the CPS And NHIS

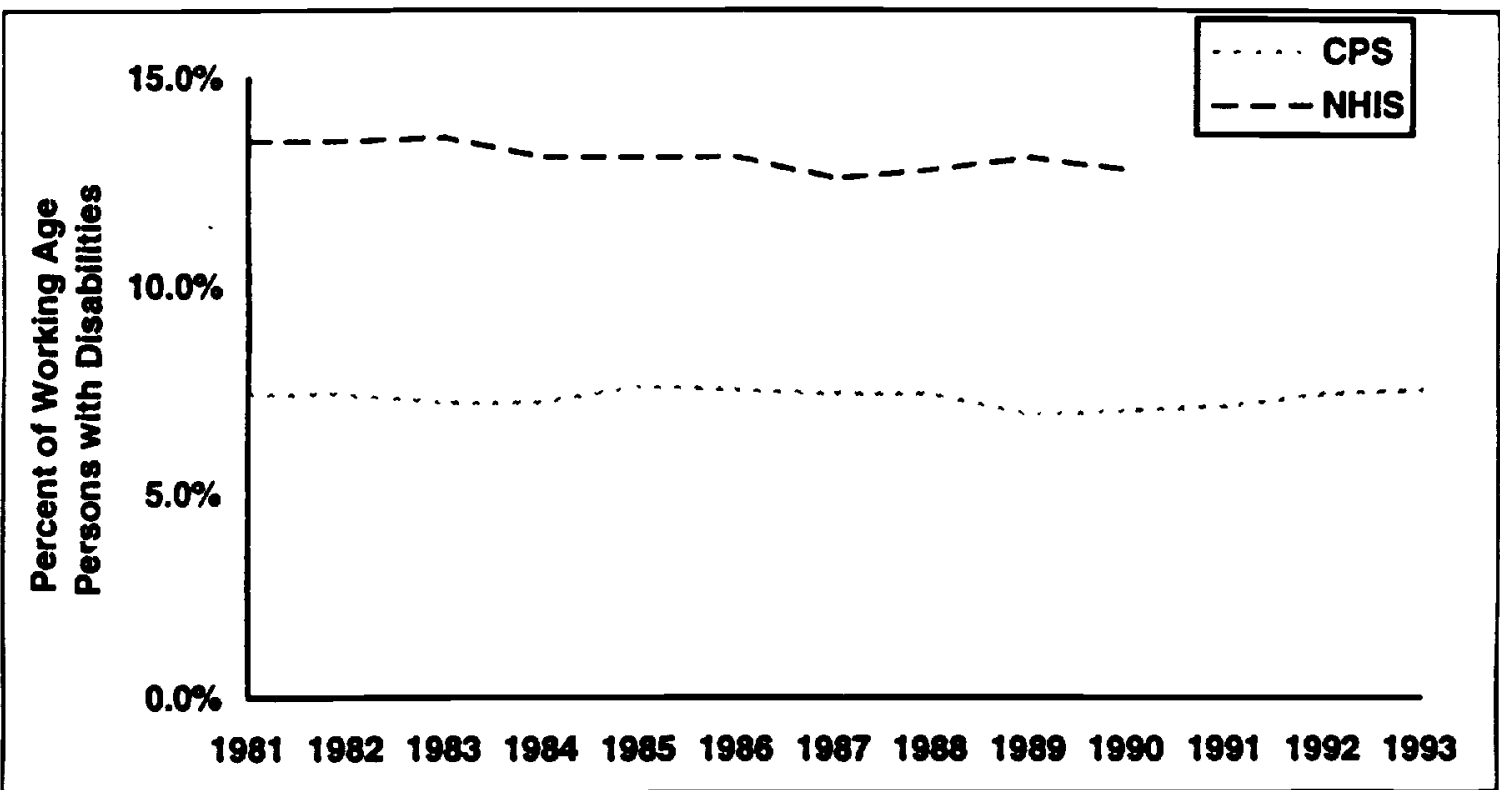

* NHIS data available only to 1990.

Source: Lewin-VHI [1994], exhibit IV.D.1. 
Figure 10

Nonparticipation in the Labor Force and Social Security Disability Recipiency, Males 45-54, 1947-82.

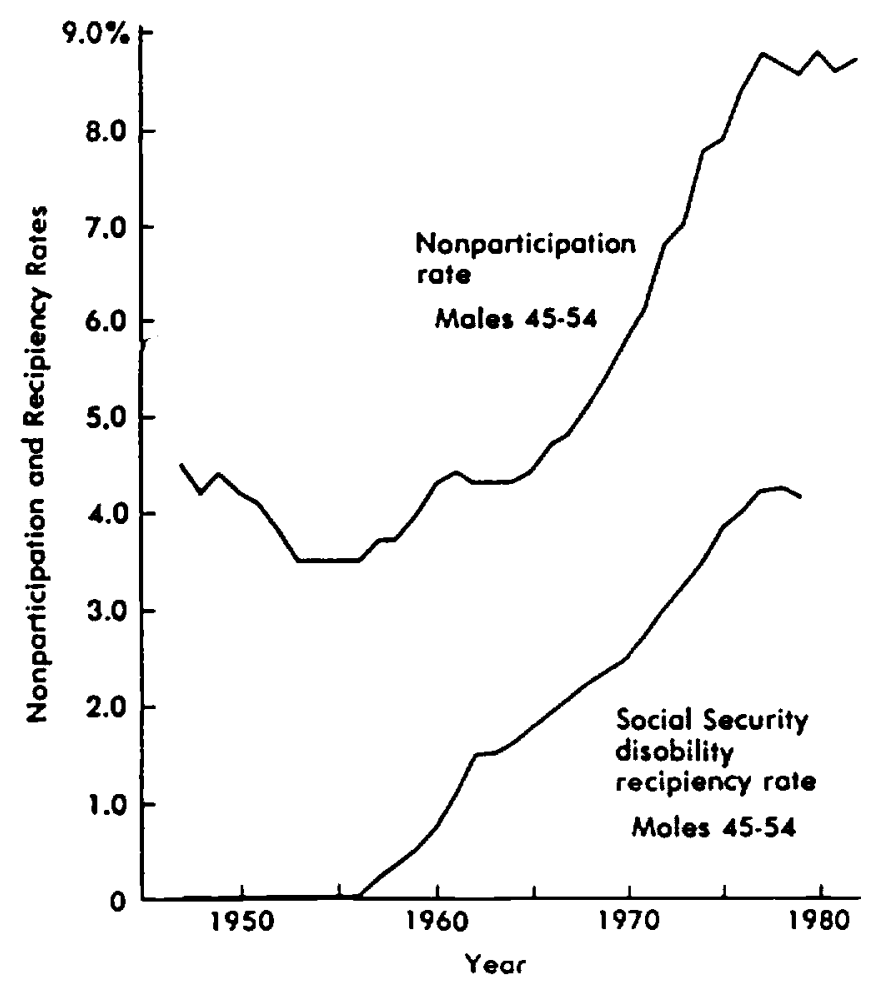

Source: Parsons [1984]. 